\title{
The influences of age on olfaction: a review
}

\author{
Richard L. Doty ${ }^{1 *}$ and Vidyulata Kamath ${ }^{1,2}$ \\ Department of Otorhinolaryngology: Head and Neck Surgery, Smell and Taste Center, Perelman School of Medicine, University of Pennsylvania, Philadelphia, PA, \\ USA \\ ${ }^{2}$ Division of Medical Psychology, Department of Psychiatry and Behavioral Sciences, The Johns Hopkins University School of Medicine, Baltimore, MD, USA
}

\author{
Edited by: \\ Gesualdo M. Zucco, University of \\ Padova, Italy \\ Reviewed by: \\ Per Moller, University of \\ Copenhagen, Denmark \\ Maria Larsson, Stockholm \\ University, Sweden \\ ${ }^{*}$ Correspondence: \\ Richard L. Doty, Department of \\ Otorhinolaryngology: Head and \\ Neck Surgery, Smell and Taste \\ Center, Perelman School of \\ Medicine, University of \\ Pennsylvania, HUP-3400 Spruce \\ Street, Philadelphia, PA 19104, USA \\ e-mail: richard.doty@ \\ uphs.upenn.edu
}

Decreased olfactory function is very common in the older population, being present in over half of those between the ages of 65 and 80 years and in over three quarters of those over the age of 80 years. Such dysfunction significantly influences physical well-being and quality of life, nutrition, the enjoyment of food, as well as everyday safety. Indeed a disproportionate number of the elderly die in accident gas poisonings each year. As described in this review, multiple factors contribute to such age-related loss, including altered nasal engorgement, increased propensity for nasal disease, cumulative damage to the olfactory epithelium from viral and other environmental insults, decrements in mucosal metabolizing enzymes, ossification of cribriform plate foramina, loss of selectivity of receptor cells to odorants, changes in neurotransmitter and neuromodulator systems, and neuronal expression of aberrant proteins associated with neurodegenerative disease. It is now well established that decreased smell loss can be an early sign of such neurodegenerative diseases as Alzheimer's disease and sporadic Parkinson's disease. In this review we provide an overview of the anatomy and physiology of the aging olfactory system, how this system is clinically evaluated, and the multiple pathophysiological factors that are associated with its dysfunction.

Keywords: age, Alzheimer's disease, anatomy, olfaction, Parkinson's disease, physiology, psychophysics, neurodegeneration

\section{INTRODUCTION}

The sense of smell determines our ability to perceive thousands of odors, including ones associated with such hazards as leaking natural gas, fire, and spoiled food. This important sense mediates, to a large degree, the flavor of foods and beverages and significantly enhances quality of life. We use this sense to confirm that our clothes, homes, and offices are clean, and to fully enjoy flowers, perfumes, festive occasions, personal care products, and nature (e.g., the mountains and the sea shore). It is perhaps not surprising, then, that smell loss or disordered smell function significantly impacts our safety, appetite, nutrition, and physical and mental well-being.

Cross-sectional studies suggest that about half of the United States population between 65 and 80 years of age has demonstrable smell loss and that, over the age of 80 , approximately threequarters experience such loss (Doty et al., 1984a; Duffy et al., 1995; Murphy et al., 2002). Somewhat lower prevalence estimates are seen in very healthy cohorts (Ship and Weiffenbach, 1993; Doty et al., 2011) and in some other populations (Bramerson et al., 2004; Karpa et al., 2010), although test methods and criteria for defining dysfunction vary considerably among studies. As a result of survivor bias and other factors, cross-sectional studies likely underestimate the prevalence of age-related olfactory dysfunction, and longitudinal studies are needed to determine incidence rates and individual changes that may occur over time from factors that damage the olfactory system (London et al., 2008). With rare exception (e.g., Schubert et al., 2011), few longitudinal studies have focused on olfactory function, per se, with most having the goal of detecting incipient dementia or other neurological disorders in older cohorts (Graves et al., 1999; Devanand et al., 2000; Wilson et al., 2007b; Herting et al., 2008; Olofsson et al., 2008, 2009; Ross et al., 2008; Schubert et al., 2008; Conti et al., 2013; Iranzo et al., 2013; Velayudhan et al., 2013). However, regardless of whether cross-sectional or longitudinal tests are employed, age-related decrements are robust and, as described later in this review, are detectable by any number of olfactory tests, including ones employing psychophysical, electrophysiological, and psychophysiological procedures. Results from most such tests are strongly correlated, reflecting, in large part, mutual dependence upon the integrity of common elements of the olfactory pathways.

The consequences of olfactory dysfunction are staggering. In addition to explaining why many older persons complain that food lacks flavor (Schiffman and Zervakis, 2002), decreased ability to smell is largely responsible for the disproportionate number of elderly who die in accidental gas poisonings and explosions each year. In Britain, $\sim 10 \%$ of all accidental deaths in the home between 1931 and 1956 occurred from coal-gas poisoning, with the majority occurring in persons over the age of 60 years (Chalke et al., 1958). Stevens et al. have estimated that $45 \%$ of older adults are unable to detect petroleum gas diluted to the level dictated by safety standards, as compared to only $10 \%$ of younger adults (Stevens et al., 1987). In a 2004 study of 445 patients with chemosensory dysfunction, a number of whom were elderly, $37 \%$ of those with olfactory impairment reported having experienced an olfaction-related hazardous event at some point in their lives, as compared to only $19 \%$ of those with no such impairment. Cooking-related incidents were most common (45\%), with 
ingestion of spoiled food (25\%), lack of ability to detect leaking natural gas (23\%), and inability to smell a fire (7\%) being less frequent (Santos et al., 2004). One longitudinal study of 1162 older individuals without dementia found that the mortality risk was $36 \%$ higher in those with low scores on a smell test after adjusting for such variables as sex, age, and education (Wilson et al., 2011a).

This review addresses the functional and pathological changes that occur in the olfactory system as a result of age. The influences of age-related diseases on olfaction, such as Alzheimer's and Parkinson's disease, are briefly mentioned but not reviewed in detail; the reader is referred elsewhere for recent reviews of such influences (Barresi et al., 2012; Doty, 2012a,b). To provide a template for understanding the neural underpinnings of agerelated changes in olfaction, we first provide an overview of basic olfactory anatomy and physiology. This is followed by the types of changes that are observed on a range of functional tests and their anatomical and neuropathological correlates.

\section{BASIC ANATOMY AND PHYSIOLOGY OF THE NOSE AND OLFACTORY SYSTEM}

The human nose is comprised of two separate nasal passages separated by a septum. An external opening, termed the naris or nostril, enters into each chamber. Extending from the lateral walls of the chambers are nasal turbinates, cartilaginous structures that are covered with a highly vascularized epithelium which serves to warm, humidify, and cleanse the air (Frye, 2003). The latter is achieved by creating turbulent flow, largely as a result of a narrowing of the cavity close to the aperture of each naris (the nasal valve). The turbulence drives particulate and other airborne matter onto the nasal mucus which is continuously moved to the gut via respiratory cilia that beat in unison (Schwab and Zenkel, 1998). Damage to respiratory cilia is associated with bacterial build-up and other problems that can impair nasal function and, ultimately, the ability to smell (Cohen, 2006).

Before an odorant is able to initiate the neural activity responsible for smell perception, it must first enter the nasal cavity from either the nares or from the nasal pharynx (i.e., from the mouth) and be absorbed into the mucus covering the olfactory epithelium. This mucus, which differs in composition from that of the mucus within the nasal cavity proper, is largely derived from specialized Bowman's glands (Getchell and Getchell, 1992). Among its secretions are odorant-binding proteins that shepherd the transit of hydrophobic odorants to the olfactory receptors (Pelosi, 1994), growth factors associated with mitosis and other cell-related processes (Federico et al., 1999), numerous immune factors (Gladysheva et al., 1986), and biotransformation enzymes involved in not only odorant clearance, but in destruction of viruses and bacteria, degradation of pro-inflammatory peptides, and toxicant metabolism (Ding and Dahl, 2003).

The cells of the olfactory epithelium are derived embryologically from both the olfactory placode and the neural crest (Katoh et al., 2011). This specialized epithelium, which lines the upper regions of the septum, cribriform plate, superior turbinate, and sectors of the middle turbinate (Leopold et al., 2000), is innervated not only by olfactory receptor cells, but by fibers from the trigeminal nerve, the nervus terminalis (Cranial Nerve 0), and autonomic fibers from the superior cervical ganglion (Zielinski et al., 1989). In addition to the receptor cells, whose cilia differ from those elsewhere in the nose in lacking dynein arms and intrinsic motility, this epithelium is comprised of sustentacular (supporting) cells, microvillar cells, basal cells, and duct cells from the Bowman's glands (Menco and Morrison, 2003). Sustentacular cells add structural support to the epithelium and, among other things, insulate receptor cells from one another. These cells are also involved in the biotransformation of noxious chemicals and maintenance of the ionic milieu that surrounds the olfactory receptor cell cilia (Vogalis et al., 2005). Two morphologically distinct types of basal cells are recognized-electron-dense horizontal cells that express cytokeratin and electron-lucent globose cells which do not express cytokeratin (Mackay-Sim, 2010). It is from these multipotent stem cells, most notably the horizontal cells, that the olfactory receptor and other cell types germinate (Iwai et al., 2008). When damaged, the olfactory epithelium can be reconstituted from these cells, although the success of such regeneration is influenced by age-related processes such as telomere shortening (Watabe-Rudolph et al., 2011) and the degree of cumulative damage from prior environmental insults, including those from pollution and viral and bacterial infections (Harkema et al., 2006). The rate of mitosis of the basal cells is regulated by multiple processes, including local cell density, resident macrophages, neural activity, and damage to olfactory sensory neurons (Camara and Harding, 1984; Mackay-Sim and Patel, 1984; Borders et al., 2007). Biochemical and mechanical stress contribute to the sensory neuron differentiation from the basal cells (Feron et al., 1999). A cross-section of the olfactory epithelium is depicted in Figure 1A, whereas the ciliated surface is depicted in Figure 1B.

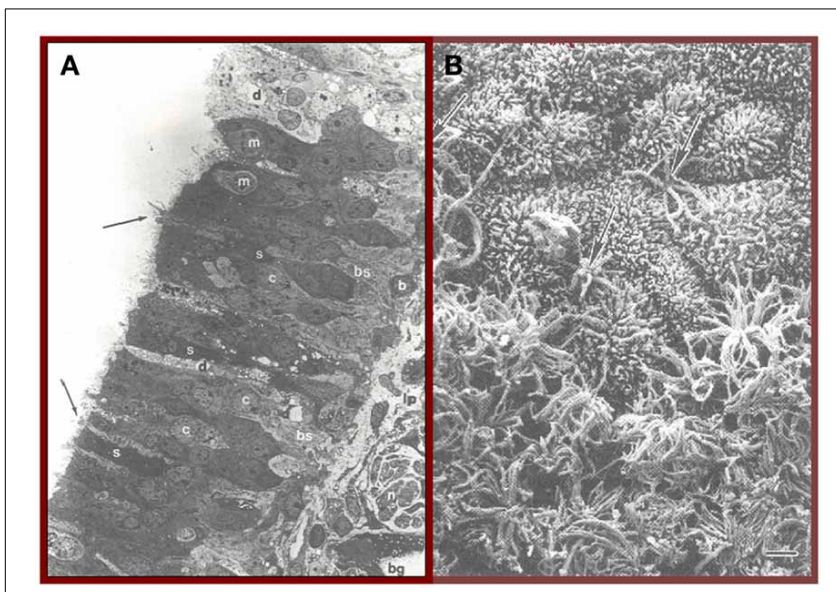

FIGURE 1 | (A) Cross-section of the human olfactory epithelium. Four main types of cells can be discerned: bipolar receptor cells (arrows point to largely denuded cilia at dendritic knobs); c, cell body, microvillar cells (m), sustentacular cells (s), and basal cells (b); bg, Bowman's gland; Ip, lamina propria; $n$, collection of axons within an ensheathing cell; $d$, degenerating cell; bs, basal cell undergoing mitosis. Photo courtesy of Dr. David Moran, Longmont, Colorado. (B) A transition zone between the human olfactory epithelium (bottom) and the respiratory epithelium (top). Arrows signify two examples of olfactory receptor cell dendrites with cilia that have been cut off. Bar $=5 \mu \mathrm{m}$. From Menco and Morrison (2003), with permission.

Copyright@2003, Marcel Dekker, Inc. 
Over 350 different functional receptor proteins are expressed in the cilia of human olfactory receptor cells (Rouquier et al., 2000). Only one type of receptor protein is embedded in the ciliary membrane of a given receptor cell (Chess et al., 1994), even though most such cells respond to a range of odorant ligands (Holley et al., 1974; Sicard and Holley, 1984). Thus, the peripheral "olfactory code" is made up of activated sets of overlapping receptor cells that can be viewed as spatial maps within both the epithelium and the olfactory bulbs (Johnson and Leon, 2007). However, coding is complex, given that more types of receptors are recruited as an odorant's concentration is increased (Malnic et al., 1999; Kajiya et al., 2001). The olfactory receptors themselves are members of the heptahelical G-protein-coupled receptor (GPCR) superfamily whose genes are distributed across all but two chromosomes, with most being on chromosome 11 and the majority of the others on chromosomes 1, 6, and 9 (Glusman et al., 2001). Odorants bind to receptor pockets located on receptor transmembrane domains 3, 5, and 6 (Saito et al., 2009). The bond is not tight, with dwell times less than a millisecond (Bhandawat et al., 2005). Transduction results from activating a GTP-binding protein which, in turn, activates type III adenylyl cyclase, catalyzing the production of $3^{\prime}, 5^{\prime}$-cyclic monophosphate (cAMP) and opening cyclic nucleotide-gated channels. This results in the cellular influx of sodium and calcium ions and depolarization of the cell (Breer, 1994). Further amplification occurs from the opening of calcium-activated chloride channels and the resultant efflux of $\mathrm{Cl}^{-}$from the cell (Stephan et al., 2009). While members of the trace amine-associated receptor (TAAR) family (Liberles and Buck, 2006) have been identified in the olfactory epithelia of a range of mammals, including humans, their role is poorly understood and ligands that activate murine TAARs do not activate intact primate orthologs (Staubert et al., 2010).

Bundles of olfactory receptor axons ultimately form the olfactory fila which are ensheathed by Schwann cell-like mesaxons, astrocytes, and fibroblasts. These bundles, which collectively make up Cranial Nerve I, aggregate beneath the basement membrane in the connective tissue-rich lamina propria and then penetrate multiple openings (foramina) of the cribriform platethe thin sector of the ethmoid bone that separates the nasal cavity from the brain (De Lorenzo, 1957). The ensheathing cells have unique properties, as they not only provide guidance to axons projecting from the nasal cavity into the brain, but, along with monocytic cells, phagocytize bacteria and other xenobiotics which might otherwise enter into the brain (Smithson and Kawaja, 2010; Panni et al., 2013). Once inside the cranial cavity, the receptor cell axons make up the first of several layers of the olfactory bulb (Figure 2) and individually ramify into the globelike glomeruli that constitute the next layer of the bulb (Meisami et al., 1998). In young persons, there are more than a thousand glomeruli, but this number decreases with age, reflecting, in part, loss of neurotrophic factors from degenerating receptor cells.

Interestingly, receptor cells that express the same receptor protein project to the same glomeruli, making the glomeruli, in one sense, functional representatives of the receptor types. The transmitter of the olfactory receptor cells, glutamate, acts upon NMDA and AMPA receptors on dendrites of projection neurons, the mitral and tufted cells. Juxtaglomerular cells modulate

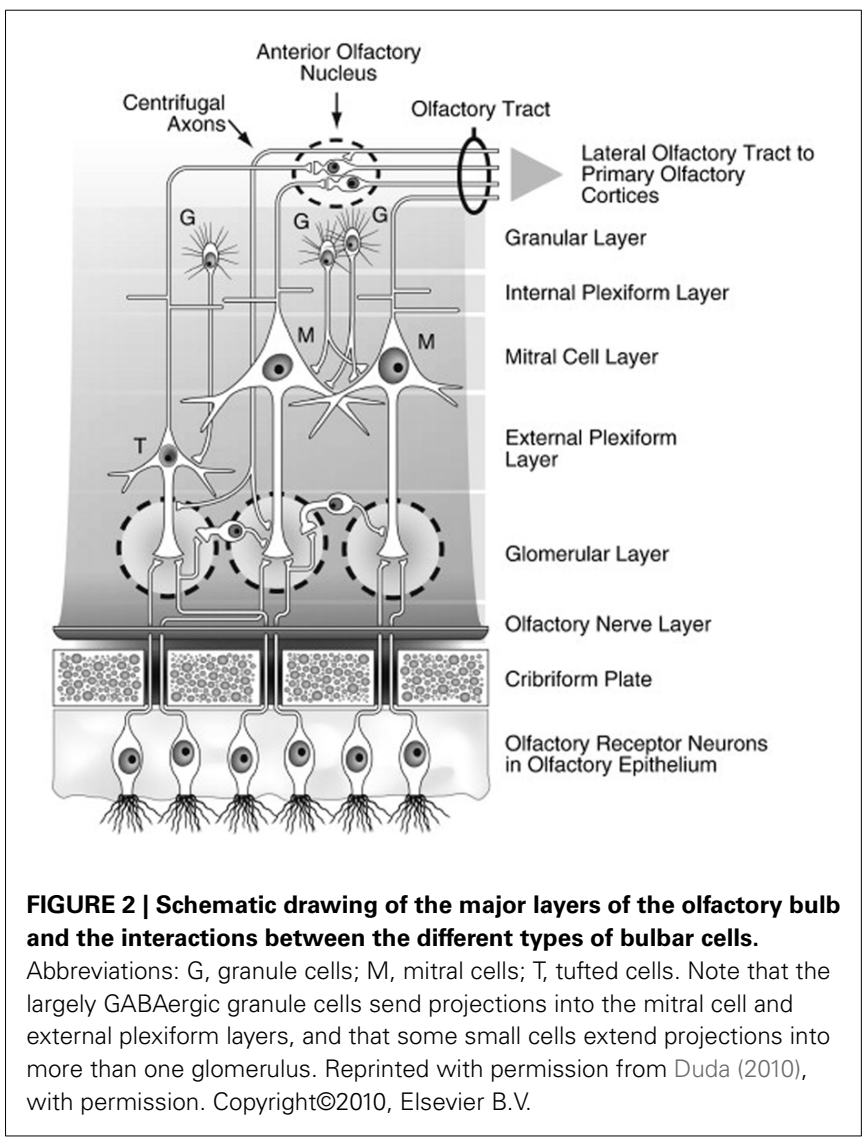

glutamate release via presynaptic $\mathrm{D}_{1}$ and $\mathrm{GABA}_{\mathrm{B}}$ receptors on the receptor cell axon terminals (O'Connor and Jacob, 2008). Similar post-synaptic modulation occurs via activation of GABA and serotonin (5HT) receptors on the mitral and tufted cell apical dendrites. Additional modulation of these cells occurs within the bulb's external plexiform layer, where their secondary dendrites form, for example, dendro-dendritic connections with GABAergic granule cells, the most numerous cells of the olfactory bulb (Shepherd, 1972). Granule cell activity is modulated primarily by centrifugal input from neurons whose cell bodies fall outside of the olfactory bulb and which are influenced by central processes, including metabolic states. Importantly, some centrifugal neurons modulate the activity of microglial cells within the bulb and elsewhere which, if not kept in check, can induce nerve cell injury via the expression of Toll-like receptors that promote pro-inflammatory and pro-apoptotic activity (Lehnardt et al., 2007; Tang et al., 2007; Ziegler et al., 2007).

Like the olfactory neuroepithelium, a number of olfactory bulb cells, most notably periglomerular and granule cells, undergo periodic replacement (Bedard and Parent, 2004). There is evidence that considerable plasticity occurs within the glomerular region of the olfactory bulb throughout life, in addition to that which occurs during early post-natal development (LaMantia and Purves, 1989; Sawada et al., 2011). In humans, as in rodents and non-human primates, neural stem cells within the anterior portion of the subventricular zone (SVZ) of the brain generate neuroblasts even in adulthood. Some of these neuroblasts, in turn, 
migrate along the rostral migratory stream (a pathway extending from the SVZ to the olfactory bulb) to ultimately repopulate interneurons within the granule and glomerular layers of the bulb (Kam et al., 2009). There is some controversy, however, as the extent and nature of this migration in humans (Wang et al., 2011a).

The mitral and tufted cell axons project to more central olfactory structures, including the anterior olfactory nucleus, the piriform cortex, the rostral entorhinal cortex, and the corticobasal nuclei of the amygdala (Cleland and Linster, 2003). Since the afferent projections of the olfactory system to the cortex bypass the thalamus, some investigators have characterized the olfactory bulb as the "thalamus of the olfactory system" (Kay and Sherman, 2007). Although most bulbar projections to the aforementioned brain regions are ipsilateral, second order projections are made to the contralateral hemisphere via the anterior olfactory nucleus and anterior commissure. Subsequent connections are formed with the orbitofrontal cortex (OFC), hippocampus, thalamus, hypothalamus, and cerebellum (Cleland and Linster, 2003). The OFC, a multimodal structure, is thought to play a vital role in flavor perception, combining input from taste, texture, and smell (Rolls and Grabenhorst, 2008). Lesions in this area impair the identification of odors and flavors (Jones-Gotman and Zatorre, 1988). Because of these connections, one investigator has noted that "existing data suggest that [olfactory testing] may actually be among the most sensitive and selective measures of OFC dysfunction" (p. 464) (Zald, 2006).

\section{AGE-RELATED OLFACTORY LOSS IN HUMANS AND ITS QUANTIFICATION}

Quantitative testing of the sense of smell, which is easy to perform in the clinic, is critical for identifying the nature and degree of smell dysfunction experienced by older persons. Many elderly fail to recognize their deficit or, when they do so, either overestimate or underestimate its magnitude. Importantly, a significant number complain of taste loss, not recognizing the primary contribution of olfaction in determining the flavor of their food. Based on quantitative testing, the clinician can inform many patients that their function, while diminished in an absolute sense, is still well above that of most of their peers, a point that provides considerable solace to those groping with the multiple changes that accompany the aging process.

Age-related deficits in olfactory function are detected by a number of types of olfactory tests, including psychophysical tests (e.g., tests of odor detection, identification, discrimination, memory, and suprathreshold intensity), electrophysiological tests (e.g., odor event-related potentials), and psychophysiological tests (e.g., odor-related changes in heart rate and respiration). All such tests generally detect age-related decrements in the olfactory system. Since hundreds of studies have documented such decrements, only selected examples are presented here.

\section{PSYCHOPHYSICAL TESTS}

Deficits observed in older persons have been most commonly detected using psychophysical tests-tests that require a conscious response on the part of the patient. With the possible exception of some measures of suprathreshold intensity and pleasantness, the results from the majority of psychophysical tests are positively correlated with one another (Doty et al., 1994; Koskinen et al., 2004), with the size of the correlations between any two tests being bounded by the reliability coefficient of the less reliable test (Doty et al., 1995). Thus, the weight of the evidence suggests that individuals have a "general olfactory acuity" factor similar to the general intelligence factor proposed for various tests of intelligence (Yoshida, 1984; Doty et al., 1994). Despite this evidence, and the fact that comparison of results from nominally disparate olfactory tests is confounded by differing reliabilities, odorants, non-olfactory task demands, and operational procedures, for heuristic reasons agerelated deficits are described below for nominally distinct classes of tests. As will be seen, age-related effects are found regardless of the employed measuring instrument, although, in general, longer tests are more reliable and, hence, more sensitive to such deficits (Doty et al., 1995).

The most widely used psychophysical tests are identification tests. A number of identification tests, such as the 40-item University of Pennsylvania Smell Identification Test (UPSIT; Figure 3) and its briefer 12-item version (the Brief Smell Identification Test or B-SIT), can be self-administered. In such tests familiar odorants are presented and the subject is required to identify the name of the odor from written alternatives or, in some cases, to choose a picture that depicts the source of the odor (Doty et al., 1984b, 1996; Richman et al., 1992; Kobal et al., 1996; Hummel et al., 1997; Nordin et al., 2002; Kobayashi et al., 2006; Krantz et al., 2009; Cameron and Doty, 2013). In addition to absolute determination of function (e.g., normal or mild, moderate, severe, or total loss), sex- and age-related normative data are available for some such tests, making it possible to determine a patient's percentile rank relative to peers (Doty, 1995). Odor identification tests are clearly sensitive to age-related

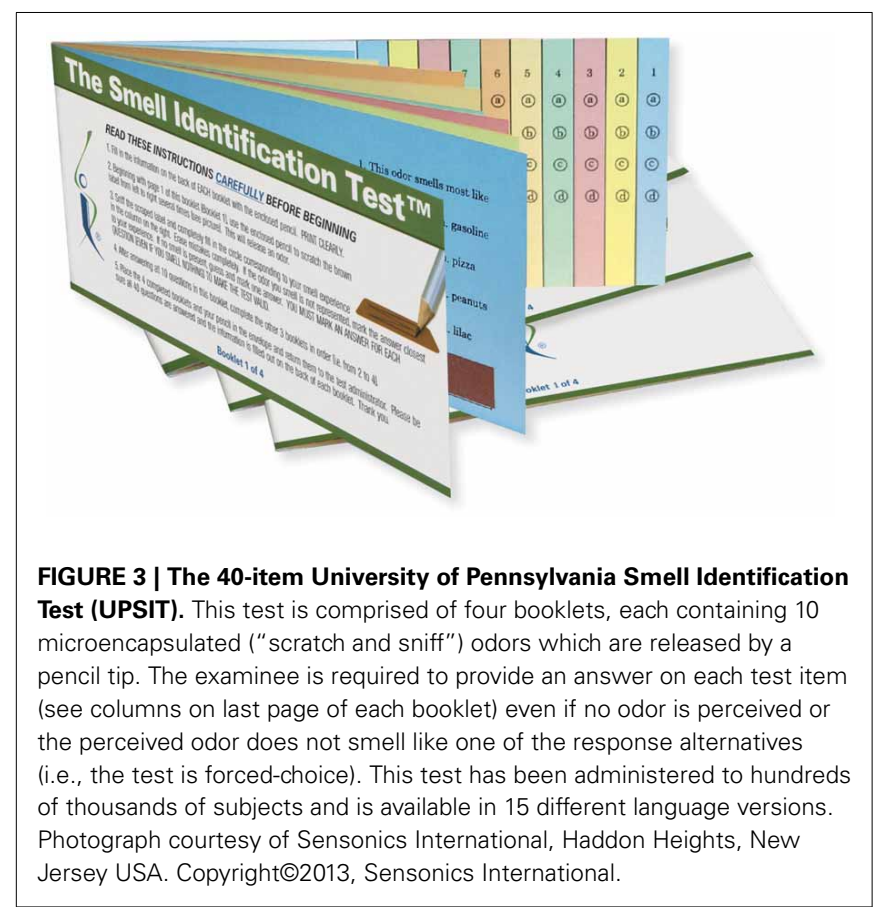


decrements in the ability to smell (Doty et al., 1984a, 2011; Cain and Stevens, 1989; Cain and Gent, 1991; Schiffman, 1991; Ship et al., 1996; Griep et al., 1997; Kaneda et al., 2000; Larsson et al., 2000; Murphy et al., 2002; Larsson et al., 2004; Calhoun-Haney and Murphy, 2005; Schumm et al., 2009; Hedner et al., 2010a,b; Olofsson et al., 2010; Wong et al., 2010; Schubert et al., 2011, 2012; Wehling et al., 2011; Wilson et al., 2011a; Menon et al., 2013; Pinto et al., 2013). Because a number of odors are not universally recognized, identification tests are often adjusted to contain odorants and response alternatives familiar to those in a given culture. An example of the prototypical age-related decrement present in odor identification is shown in Figure 4 (Doty et al., 1984a).

Odor threshold tests are conceptually analogous to pure-tone hearing threshold tests, except that the stimuli consist of a range of concentrations of an odorant, rather than a range of tones. Unlike most auditory threshold tests, forced-choice testing is usually employed. In a given test, a series of different concentrations of an odorant are presented to a subject via sniff bottles, squeeze bottles, felt-tip pens, or olfactometers, such as the one depicted in Figure 5. Dilutions are commonly made in half-log steps using mineral oil, propylene glycol, or other liquids as the dilution media. The goal of the test is to detect the lowest odorant concentration that can be reliably detected (detection threshold) or recognized (recognition threshold) (Cain et al., 1983; Doty et al., 1984b; Takagi, 1989; Doty, 1995; Hummel et al., 1997).

As with odor identification tests, significant age-related alterations are generally observed regardless of the psychophysical paradigm used to establish the threshold (Chalke et al., 1958; Fordyce, 1961; Joyner, 1963; Kimbrell and Furchtgott, 1963; Venstrom and Amoore, 1968; Strauss, 1970; Schiffman et al., 1976; Murphy, 1983; Van Toller and Dodd, 1987; Cain and Gent, 1991; Stuck et al., 2006; Larsson et al., 2009), with somewhat lower thresholds (greater sensitivity) in the healthiest cohorts (Griep et al., 1997). Studies that have explored a spectrum of

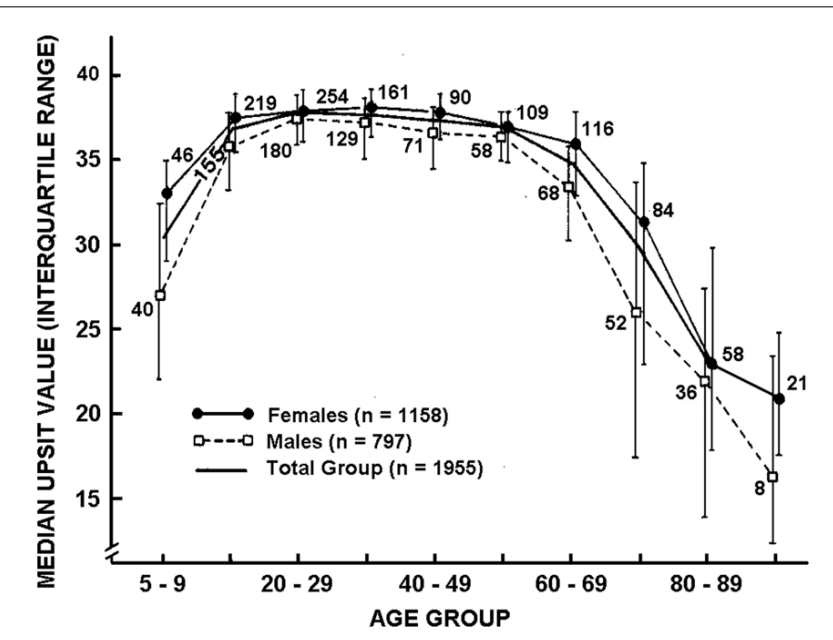

FIGURE 4 | Scores on the University of Pennsylvania Smell Identification Test (UPSIT) as a function of age and gender in a large heterogeneous group of subjects. Numbers by data points indicate sample sizes. From Doty et al. (1984a), with permission. Copyright@1984, American Association for the Advancement of Science. ages typically report age-related performance functions similar to those depicted for odor identification (Figure 3), although such functions depend upon the involved odorant (Venstrom and Amoore, 1968; Deems and Doty, 1987).

Suprathreshold odor discrimination tests require the subject to discriminate among sets of odorants or odorant mixtures, for example by identifying the "odd" stimulus or set of stimuli from foils (Jehl et al., 1995; Kobal et al., 2000; Weierstall and Pause, 2012). In some instances, similarities among odorants are established and the similarity ratings or correlations subjected to statistical procedures such as multidimensional scaling, a procedure that aids in visualizing how well the stimuli can be differentiated from one another (Schiffman and Leffingwell, 1981). Older persons, on average, are less able than younger ones to discriminate between stimuli (Schiffman and Pasternak, 1979). Some match-to-sample discrimination tests intersperse differing delay intervals between the inspection odor and response set (Bromley and Doty, 1995; Choudhury et al., 2003). The goal is to assess the ability to remember the inspection odor and chose it from foils. However, the odor memory component of such tests can be confounded with semantic issues (e.g., labeling an odor with a name and then remembering the name of the odor whose memory is already present in long-term memory stores) (Jonsson et al., 2011). Such confounding can be overcome to some degree by using unfamiliar odorants that are difficult to consistently label or by employing incidental memory tasks (Møller et al., 2004, 2007).

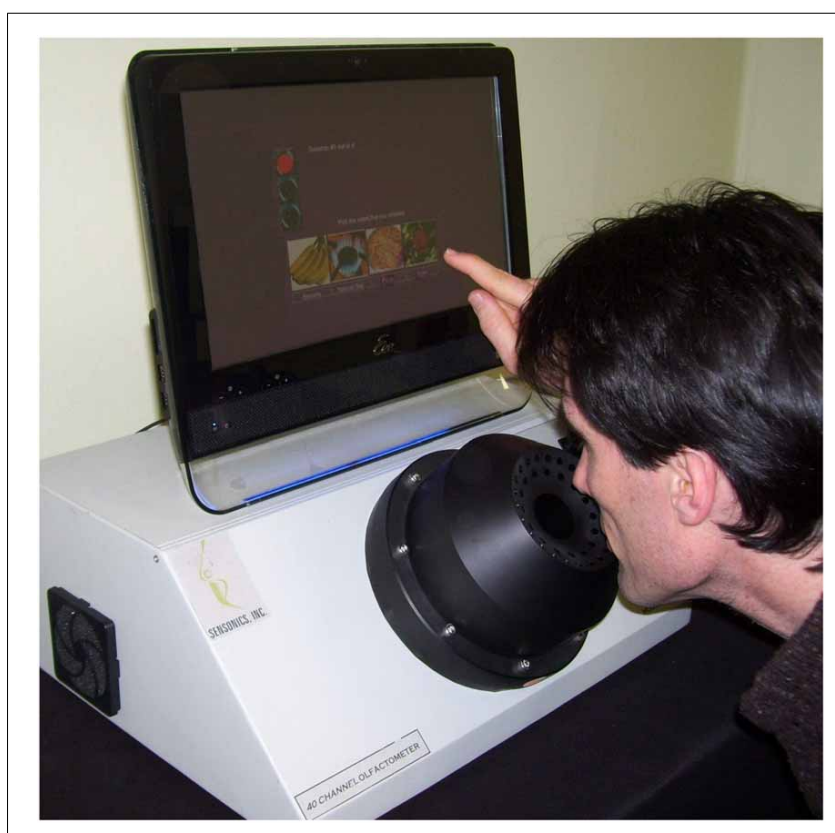

FIGURE 5 | The Self-administered Computerized Olfactory Testing System (SCOTS). This modern olfactometer allows for self-administration of olfactory threshold tests, among other types of tests, and automatically calculates the threshold value based upon subject responses. This system eliminates administrator error in the presentation of test stimuli and provides exacting control of stimulus duration, inter-stimulus intervals, and other factors. Photograph courtesy of Sensonics International, Haddon Heights, New Jersey USA. Copyright@2013, Sensonics International. 
An example of the influences of age and sex on an odor discrimination/memory test is presented in Figure 6. In this study, no effects of 10,30, and 60 s delay intervals were observed, supporting the view that short-term odor memory is not affected in most persons and that performance differences in match-tosample tests largely reflect discrimination, per se (Engen et al., 1973; Choudhury et al., 2003). It should be emphasized that it is probably impossible to completely disassociate memory processes from other nominal forms of odor perception, since memory is involved in most olfactory tasks and consciousness itself is, in effect, a form of memory. Importantly, age-related deficits in odor recognition may be a reflection of greater difficulties in recalling odor knowledge or names than in poorer ability to perceive or recognize the involved odors (Larsson et al., 2006).

Suprathreshold measures of the perceived strength of odors, as assessed using rating scales and magnitude estimates, have been shown to be sensitive to age in some, but not all, studies. Differences in procedures, odorants assessed, and sample sizes likely explain such discrepancies. In a study of over 26,000 respondents to a scratch-and-sniff odor survey of members of the National Geographic Society, ratings of the strength of single concentrations of six odorants were obtained using a 5-point rating scale (Wysocki and Gilbert, 1989). Age-related declines in the ratings were most noticeable for mercaptans (26\% decline over the life span) and amyl acetate (22\% decline), with less decline occurring for eugenol (14\%), rose (13\%), androstenone $(10 \%)$, and Galaxolide (3\%). Those odorants that showed the least decline were initially rated as less intense and were usually more difficult for older persons to identify. Importantly, when the data from the six stimuli were averaged, the age-related declines in the odor ratings began for males in their 20's and for females in their 40's.

Findings from studies assessing age-related changes in perceived intensities across multiple suprathreshold odorant concentrations have been variable. Most studies have employed

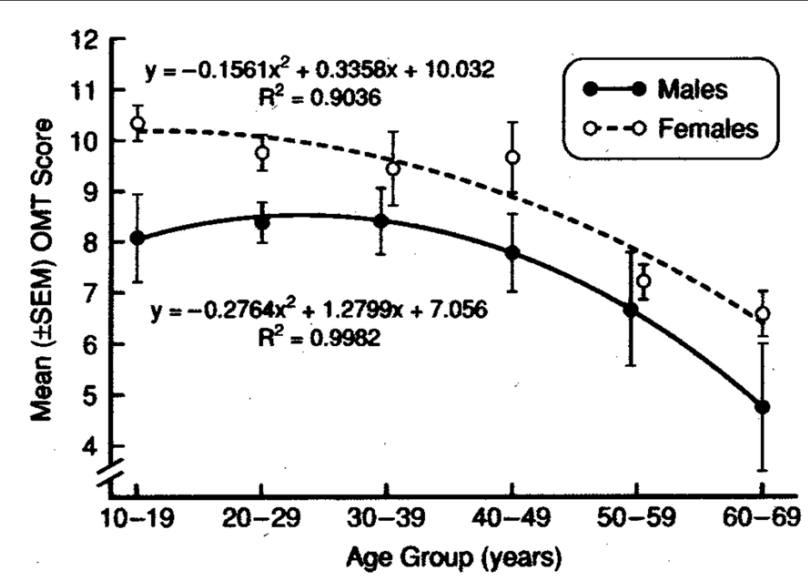

FIGURE 6 | Test scores for men and women on a 12-item odor discrimination/memory test as a function of age. Note age-related decline in performance and the fact that women outperform men at all ages. Data are collapsed over 0-, 30- and 60-s delay intervals. From Choudhury et al. (2003), with permission. Copyright@2003, Oxford University Press. magnitude estimation procedures to assess the build-up of stimulus intensity as odorant concentration is increased. In the classical magnitude estimation procedure, subjects are instructed to assign numbers in proportion to the relative perceived intensity of different concentrations of an odor (e.g., if a stimulus smells twice as strong as another, a number twice as large is assigned, and so on) (Doty and Laing, 2003). Each subject is allowed, in most instances, to choose the specific numbers they wish to employ (the "free modulus" method). In some cases, responses other than numbers are used, such as pulling a tape measure a distance proportional to the perceived intensity. Murphy (1983), using the mixed olfactory/trigeminal stimulant menthol, found the slope of the stimulus:response magnitude estimation function of 10 older persons to be less steep than that of 10 younger persons. However, other investigators have not observed such stark slope differences. In a study of 120 subjects ranging from 6 to 94 years of age, for example, magnitude estimates made to various concentrations of 1-propanol were unrelated to age, leading the authors to erroneously conclude that age did not influence olfaction (Rovee et al., 1975). Similarly unimpressive age-related effects were observed in a study of 137 subjects that assessed the intensities of phenyl ethyl alcohol and pyridine (Cowart, 1989). Stevens et al., in a study of 20 young and 20 old subjects, also found no strong evidence for meaningful age-related altered slopes in stimulus:response functions for amyl butyrate, a relatively non-pungent odorant, or $\mathrm{CO}_{2}$, a strong trigeminal stimulant (Stevens et al., 1982). However, by using the method of cross-modal matching, the relative position of parallel stimulus:response functions was found to differ between the young and old subjects (Figure 7). In this procedure, low pitch broad-band tones were interspersed among the odorant concentration trials and the subjects were required to estimate the intensities of both the tones and the smells relative to one another. Under the assumption that the broad-band low frequency tones were not markedly influenced by age, differences in

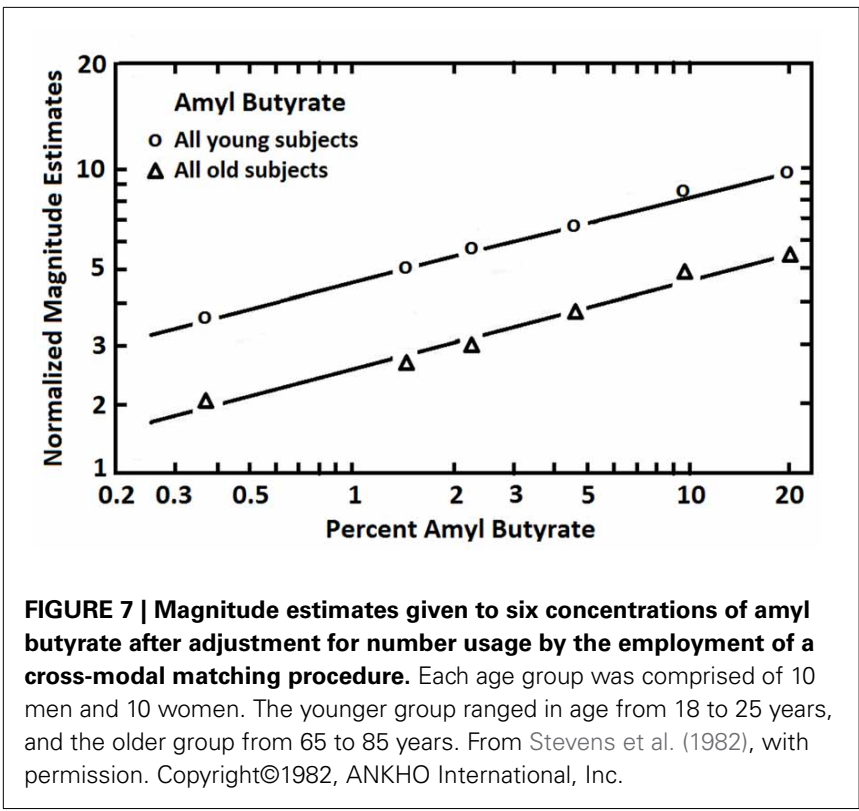


idiosyncratic number usage could be taken into account, allowing an assessment of the magnitude of absolute odor intensity estimates. As is clear from Figure 5, the percentage decrement in strength observed in older subjects was uniform across concentrations. Similar findings have been noted in cross-modal matching studies for amyl acetate, amyl butyrate, benzaldehyde, ethyl alcohol, limonene, and pyridine (Stevens and Cain, 1985).

\section{ELECTROPHYSIOLOGICAL TESTS}

Odor-induced recordings have been obtained from electrodes placed near or on the olfactory epithelium, producing a summated negative potential termed the electro-olfactogram (EOG) (Hosoya and Yashida, 1937; Ottoson, 1956). EOG magnitude is proportional to stimulus concentration and is correlated with perceived intensity, although it can be present even after death, suggesting it alone cannot be relied upon as a measure of odor perception, per se. Recording can be tedious and activity in one area of the olfactory epithelium is not necessarily representative of activity in other areas. Although one can surmise from the age-related general decreases in the integrity of the olfactory epithelium that EOGs would be expected to be smaller, to our knowledge no such study has been performed. It is noteworthy, however, that EOG activity is found on the anterior surface of the middle turbinate and a few millimeters below the anterior insertion of the middle turbinate, suggesting, along with biopsy samples, that the olfactory epithelium extends farther forward in some people than traditionally believed (Leopold et al., 2000).

A more practical electrophysiological procedure is the measurement of odor-induced electrical activity at the level of the scalp (e.g., the odor event-related potential or OERP). This activity reflects odor-related changes induced in electrical fields generated by large populations of cortical neurons (Gevins and Remond, 1987). However, the signals are small $(<50 \mu \mathrm{V})$, can be difficult extract from the background EEG, and require complex stimulus presentation equipment (Figure 8). In one study, for example, OERPs were not identifiable in nearly a third of subjects with no olfactory deficits (Lotsch and Hummel, 2006). Nevertheless, age-related alterations in the latency and amplitude of OERPs have been observed, with older persons typically exhibiting longer N1 latencies and smaller N1 and P2 amplitudes (Figure 9) (Murphy et al., 1994; Evans et al., 1995; Hummel et al., 1998; Covington et al., 1999; Thesen and Murphy, 2001; Stuck et al., 2006; Morgan and Murphy, 2010). Although classic procedures analyze only time-locked potentials, recently developed procedures combine traditional EEG and OERP methodology to assess activity within both time and frequency domains (Huart et al., 2012; Osman and Silas, 2014). Age-related responses using these newer methods have yet to be assessed.

\section{PSYCHOPHYSIOLOGICAL TESTS}

Psychophysiological tests are tests which measure mainly autonomic nervous system responses to stimuli, in this case odor. Among such measures are changes in heart rate (Bensafi et al., 2002), blood pressure (Nagai et al., 2000), respiration (Kleemann et al., 2009), and skin conductance (Møller and Dijksterhuis, 2003). In the case of the nose, cardiovascular and respiratory

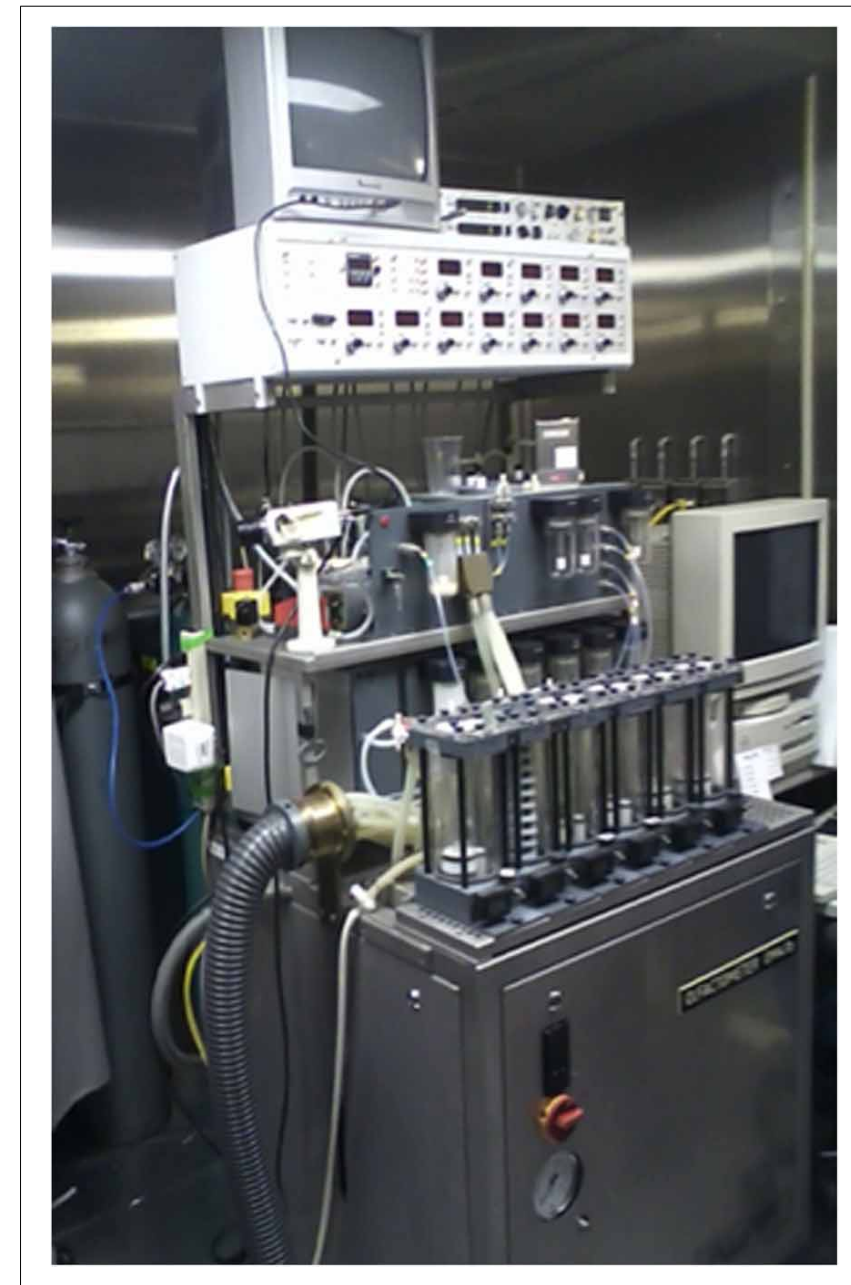

FIGURE 8 | Air-dilution olfactometer used to present pulses of odorants into a purified and humidified airstream directed through nares of a subject. This device ensures that the odor event-related potentials (OERPs) are not confounded by somatosensory artifacts due to alterations in stimulus pressure, temperature, or other factors. Photo courtesy of the University of Pennsylvania Smell and Taste Center, Philadelphia, PA.

changes can reflect activity of the trigeminal nerve $(\mathrm{CN} \mathrm{V})$, rather than the olfactory nerve $(\mathrm{CN} \mathrm{I})$, limiting in some cases the usefulness of such tests (Allen, 1928).

A recently developed test measures a basic respiratory response to smelling an unpleasant odor (Frank et al., 2003, 2004, 2006). In this test, called the Sniff Magnitude Test, the subject sniffs a canister. Upon the initiation of the sniff, which is detected by air pressure changes sensed by cannulas positioned just inside the nose, the canister opens and either odorless air or a bad smelling odorant (e.g., methylthiobutyrate or ethyl 3-mercaptoproprionate) is released. Persons with a good sense of smell immediately stop sniffing, whereas those with a poor sense of smell take longer to inhibit their sniff or, if anosmic, may not inhibit their inhalation at all (Tourbier and Doty, 2007). The magnitude and duration of the sniff is assessed by a computer and a ratio computed between the area of the sniff pressure-time curve on odorant trials to that 
on blank air trials. Like other olfactory measures, this measure is sensitive to age-related olfactory changes (Figure 10) (Frank et al., 2006).

\section{CAUSES OF AGE-RELATED OLFACTORY LOSS}

It seems intuitive that structural changes would be present in the aging nose and olfactory system that would explain the functional declines observed in older persons. Indeed, as described below, a number of age-related alterations within the nose, olfactory epithelium, bulb, and higher brain structures have been associated to one degree or another with olfactory dysfunction. Moreover, several genes have been found to contribute, albeit to a modest degree, to the age-related decline in odor identification.
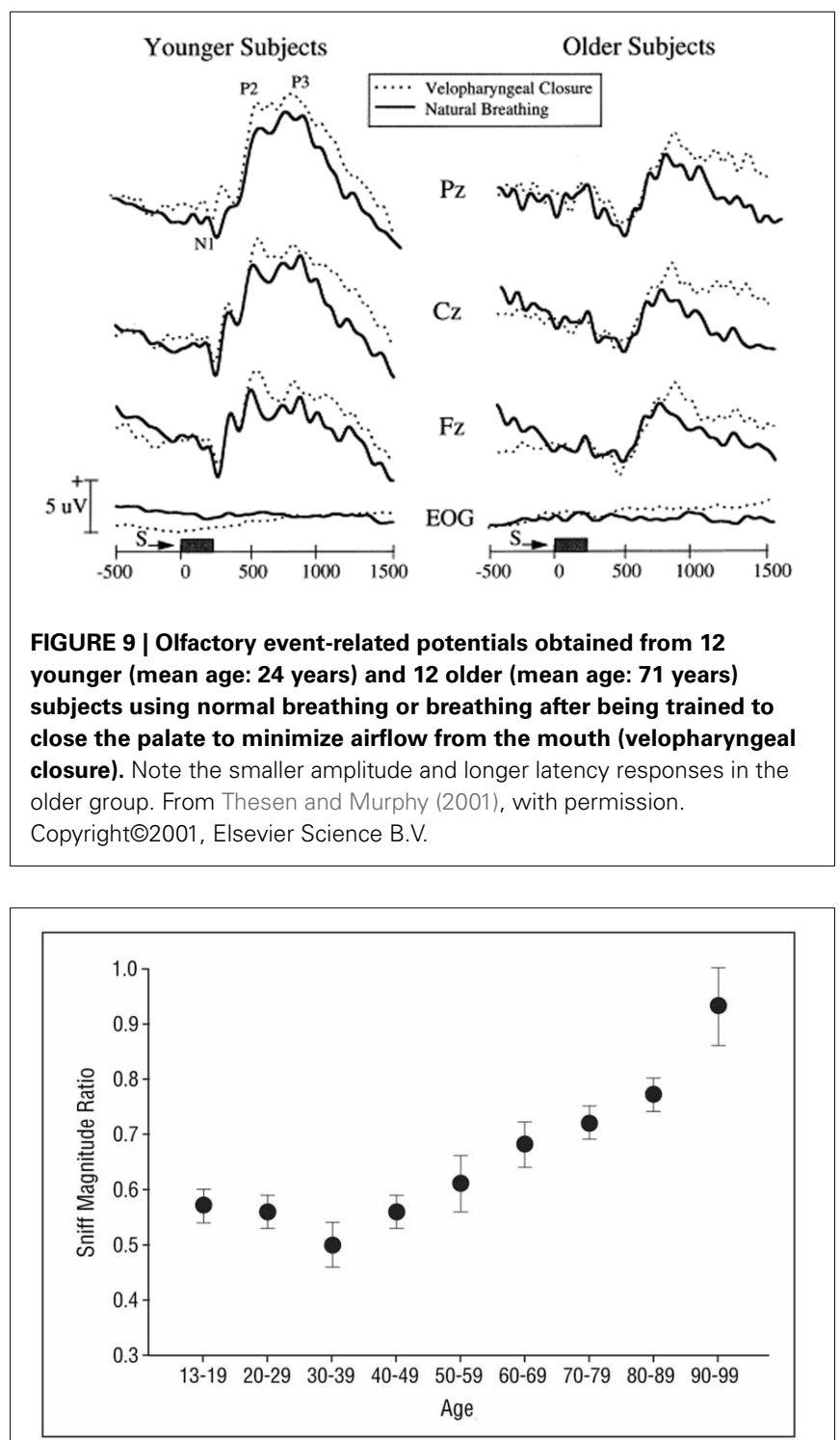

FIGURE 10 | Mean (s.e.m.) sniff magnitude ratios obtained from the Sniff Magnitude Test as a function of age. Sample size $=137$ subjects, $74 \%$ of whom were female. From Frank et al. (2006), with permission. Copyright@2006, American Medical Association.
For example, persons over the age of 70 who are homozygous for the val allele of the val66met polymorphism of brain derived neurotrohic factor (BDNF) exhibit a somewhat greater 5-year decline in odor identification performance than persons heterozygous for this allel $(\mathrm{v} / \mathrm{m})$ or homozygous for the met allel $(\mathrm{m} / \mathrm{m})$ (Hedner et al., 2010b). Older carriers of the $\varepsilon 4$-allele of the human apolipoprotein E gene, a plasma protein involved in lipid transport, exhibit greater longitudinal declines in odor identification than non-carriers (Calhoun-Haney and Murphy, 2005). This occurs even after controlling for the effects of vocabulary and general cognitive status, suggesting that the influences of this allele on odor identification ability are independent of clinical dementia (Olofsson et al., 2010).

More recently, Doty et al. tested the odor identification ability of 1222 very old twins and singletons, including 91 centenarians (Doty et al., 2011). Unlike cognition, the sex- and ageadjusted heritability coefficients for odor identification from the two genetic models employed were quite low (i.e., 0.13 and 0.16 compared to 0.70 for cognition). These authors point out that nearly all twin studies looking at middle aged or older study cohorts report low heritability coefficients, in contrast to studies in which only young cohorts are assessed. One explanation for this observation is that the initial effects of heritability on function are eventually swamped by other factors in older persons, including the cumulative environmental insults to the olfactory epithelium, as described below.

\section{CHANGES IN NON-OLFACTORY ELEMENTS OF THE NOSE}

Odorant access to the olfactory receptors can be altered by agerelated changes in nasal airflow patterns and mucous composition, including those associated with diseases which are more common in the elderly. The prevalence of chronic rhinosinusitis, nasal polyposis, and lessened mucocilliary clearance increases with age (Settipane, 1996; Cho et al., 2012), as does nasal resistance, as measured by rhinomanometry (Edelstein, 1996). The nasal epithelium undergoes age-related atrophy, decreases in mucosal blood flow, and decrements in elasticity (Somlyo and Somlyo, 1968; Bende, 1983). In general, older persons report experiencing more frequent episodes of postnasal drip, nasal drainage, sneezing, and coughing than younger ones (Edelstein, 1996). Interestingly, increased age is associated with a significant decrease in asthma (Jarvis et al., 2012) and a number of abnormalities of the nasopharynx, such as adenoidal hypertrophy, inflammation, cystic degeneration, or thick mucus discharge (Edelstein, 1996). Recently it has been shown that sleep apnea, a disorder associated with restriction of nasal airflow that increases in prevalence with age, has an adverse effect on smell function (Salihoglu et al., 2013).

It must not be forgotten that the nose is a dynamic organ. Airflow patterns are regularly shifting, reflecting multiple influences on nasal turbinate engorgement and secretory activity from air temperature, humidity, physical activity, psychological stress, and environmental xenobiotics such as allergens, nanoparticles, toxic chemicals, and infectious agents (Frye, 2003). Nasal engorgement is regulated in large degree by the autonomic nervous system. Thus, relative sympathetic/parasympathetic dominance influences the lateralized changes in engorgement of the 
nasal capillary bodies that occur over time. Although reciprocal and cyclic left:right fluctuations in relative airflow-termed the nasal cycle-are not as common as previously believed (Gilbert, 1989; Mirza et al., 1997), there is evidence that olfactory sensitivity is somewhat higher during the so-called sympathetic phase of this putative cycle, i.e., when the left side of the nose is relatively more engorged than the right (Frye and Doty, 1992). Since nearly three-quarters of adults over the age of 50 no longer exhibit this cycle (Mirza et al., 1997), a subtle lowering of olfactory sensitivity could mark the transition from the predominance of relative more sympathetic dominance to a more balanced sympathetic/parasympathetic mode. Age-related changes the suprachiasmatic nucleus, a brain center involved in the control of a number of biological rhythms, could conceivably account for this effect (Farajnia et al., 2014).

An important non-neural process that undoubtedly compromises smell function is the age-related decline in the size and number of patent foramina of the cribriform plate (KrmpoticNemanic, 1969; Kalmey et al., 1998). The occlusion or decrement in size of these holes can lead to a pinching off or elimination of olfactory receptor cell axons that enter into the brain from the olfactory epithelium (Figure 11). Kalmey et al. found a $47.3 \%$ reduction of the area of the foramina within the posterior centimeter of the cribriform plate in men older than 50 years relative to those younger than this age $\left(7.19\right.$ vs. $\left.3.79 \mathrm{~mm}^{2}\right)$ (Kalmey et al., 1998). The reduction in women was $28.8 \%$ (5.61 vs. $\left.3.99 \mathrm{~mm}^{2}\right)$.

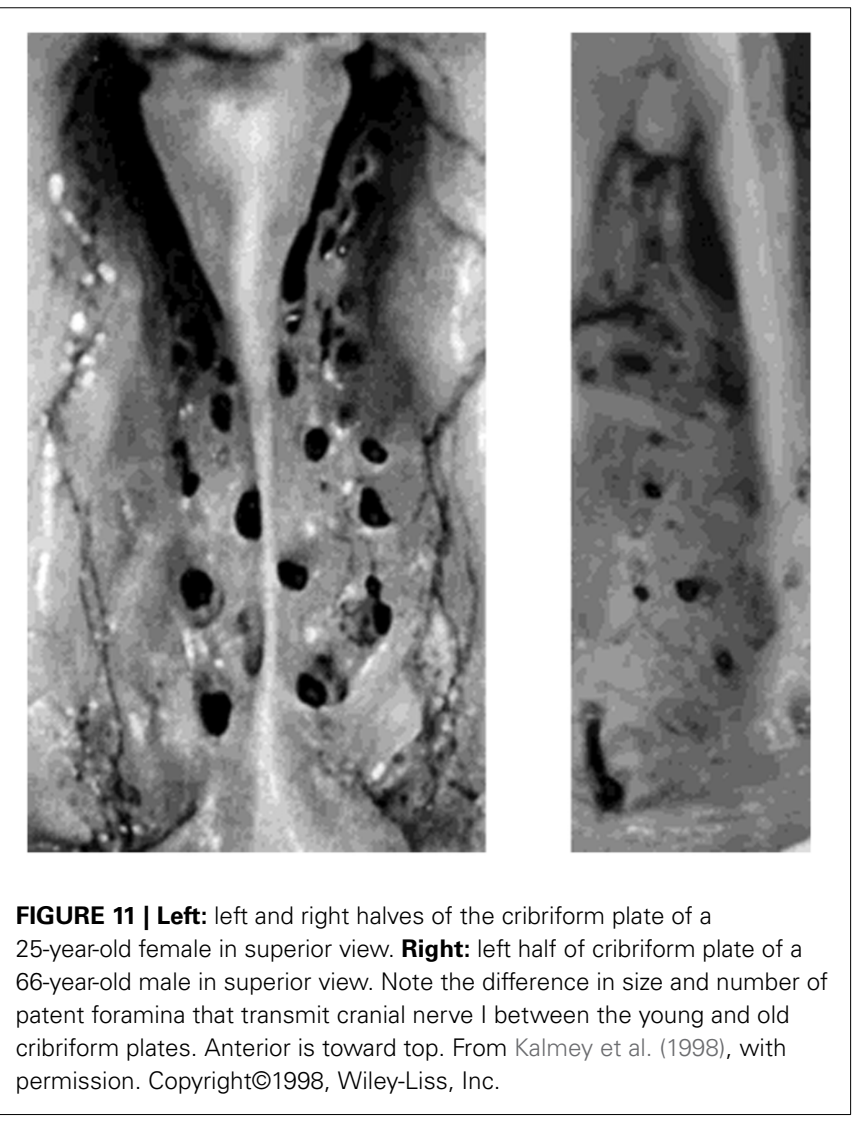

As described in the next section, the olfactory neuroepithelium becomes compromised as we age. While there are multiple reasons for this compromise, it is clear that the clearance of bacteria and other agents from the nasal cavity — clearance that depends in large part on the nature of the mucus and mucocilliary activitychanges across the lifespan. In one study of adults ranging in age from 18 to 100 years, for example, mucociliary function was found to be impaired in about $30 \%$ of those 60 years of age and older (Sakakura et al., 1983).

\section{CHANGES IN THE OLFACTORY NEUROEPITHELIUM}

Histological studies of the human olfactory epithelium have shown age-related changes in its nature and integrity, including decreased number of receptors, a thinning of the epithelium in general, and alterations in the cellular patterns and zonal distributions of the nuclei of the olfactory receptor and sustentacular cells. Intermingling of supporting and receptor cell nuclei are common, as is intercalation of respiratory epithelium with that of the olfactory epithelium, reflecting replacement of the olfactory epithelia with respiratory epithelia (Naessen, 1971; Nakashima et al., 1984; Morrison and Costanzo, 1990; Paik et al., 1992) (Figure 12). Similar alterations are noted in rodents exposed to olfactory toxins such as 3-methyl indole and 3-trifluoromethyl pyridine (Gaskell et al., 1990; Peele et al., 1991). In infancy and early childhood, the olfactory epithelium is highly vascularized, with blood capillaries being found in its basal layers and in close association with the perikarya of the receptor cells (Naessen, 1971). With age, these intraepithelial vessels regress and the epithelium becomes avascular. In adulthood, pigment granules are evident in the cytoplasm of sustentacular cells-granules that increase in number in the elderly (Naessen, 1971).

There are a number of reasons for the age-related decline in olfactory receptor cells and other elements of the olfactory epithelium. First, neurogenic processes appear to be compromised with age. In the rat, the ratio of dead or dying cells to the number of live receptor cells increases with aging (Mackay-Sim, 2003), suggesting the possibility that receptor cells from older individuals have less mitotic activity than those from younger individuals. This is in accord with the observation that following chemical destruction of the olfactory receptors of mice with zinc sulfate or methyl-formimino-methyl ester, morphological repair is slower or nonexistent in older animals (Matulionis, 1982; Rehn et al., 1986). Second, the aforementioned age-related decline in the size and number of patent foramina of the cribriform plate may result in necrosis of the olfactory receptor cells, eliminating them from the olfactory epithelium (Krmpotic-Nemanic, 1969; Kalmey et al., 1998). Third, immunologic and enzymatic defense mechanisms critical for maintaining the integrity of the epithelium become compromised with age. For example, age-related reductions have been found in the expression of phase I and phase II xenobiotic metabolizing enzymes, including carnosinase, glutathione, S-transferases, heat-shock protein 70, and isoforms of cytochrome P-450 (Kirstein et al., 1991; Getchell et al., 1995; Krishna et al., 1995). Fourth, age-related losses occur in the specificity of the responses of individual receptor cells. For example, electrophysiological tuning curves are broader in biopsied receptor cells from older than from younger persons (Rawson et al., 


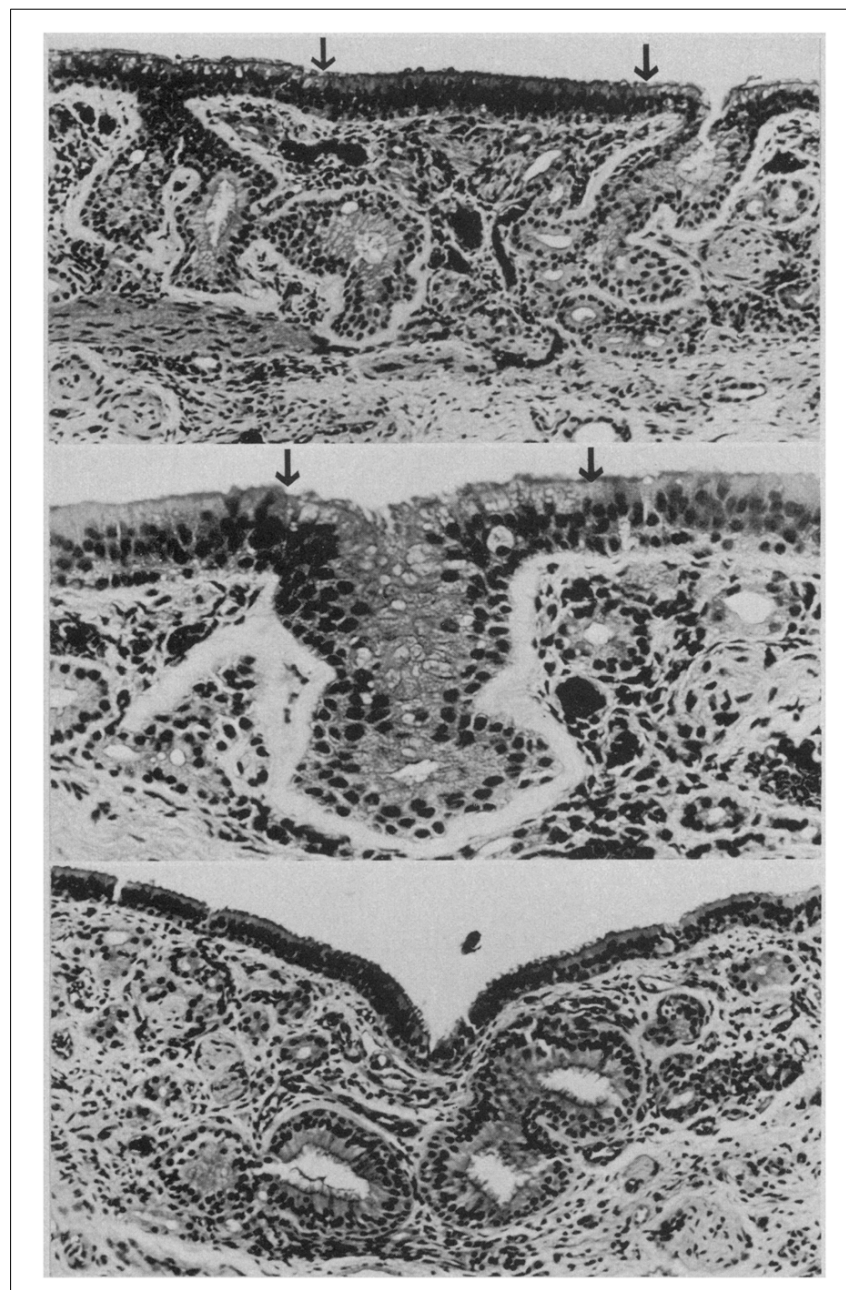

FIGURE 12 | Respiratory epithelium in the olfactory region of the adult human. Top: ciliated and goblet cell-containing respiratory epithelium has invaded degenerated olfactory neuroepithelium (between arrows). Arrows indicate junction of respiratory and olfactory epithelia (HandE, $\times 100$ ). Middle: gland-like invagination (between arrows) of respiratory epithelium into the lamina propria $(\mathrm{HandH}, \times 200)$. Bottom: gland-like respiratory epithelium with large lumina in the lamina propria $(\mathrm{HandE}, \times 1000)$. From Nakashima et al. (1984), with permission. Copyright@1984, American Medical Association.

1998). Fifth, exposures to air-borne environmental agents, including air pollution, cigarette smoke, viruses, bacteria, and other xenobiotics, damage regions of the olfactory epithelium, having more functional consequence in later years when their cumulative effects have taken a toll on the epithelium (Smith, 1942; Hirai et al., 1996; Loo et al., 1996). As mentioned earlier, environmental factors likely swamp age-related genetic factors in determining the degree of olfactory function in later life (Doty et al., 2011). Thus, Loo et al. found no age-related decrement in the number of mature olfactory neurons in the olfactory mucosa in rats reared in a pathogen-free environment, unlike the situation in rats reared in a normal laboratory environment (Loo et al., 1996).

\section{CHANGES IN THE OLFACTORY BULB}

In parallel with the integrity of the olfactory epithelium, the size of the olfactory bulb and a number of its laminae-most notably the glomerular layer-declines with age in humans and other animals (Bhatnagar et al., 1987; Yousem et al., 1998; Sama et al., 2008). While this decline may reflect, to some degree, generalized atrophy, loss of neuronal elements, and increases in astroglia, most of the decline appears to be secondary to damage to the olfactory neuroepithelium from nasal infections, chronic rhinitis, lack of airflow, and exposures to xenobiotics; (see Holt, 1917; Frühwald, 1935; Smith, 1935; Meurman, 1950; Liss and Gomez, 1958). Indeed, one can use the number of glomeruli of autopsy specimens to infer the amount of destruction of the olfactory epithelium. In a classic study, Smith (1942) did just that, counting the number of glomeruli to estimate age-related losses of human olfactory receptors. In his examination of 205 olfactory bulbs from 121 autopsy specimens, he concluded that the loss of the olfactory nerves begins soon after birth and continues throughout life at the rate of approximately $1 \%$ per year. However, considerable variability was noted at all ages and a reassessment of his data using medians rather than means suggests that glomerular loss is most evident after the fifth decade of life, more or less paralleling what is shown in Figure 3 for odor identification.

Bhatnagar et al. (1987) quantitatively assessed the morphology of eight pairs of bulbs from women who died between the ages of 25 and 102 years. Corresponding bulb volumes, estimated for the ages of 25,60 , and 95 years by linear regression, were 50.02 , 43.35 , and $36.68 \mathrm{~mm}^{3}$. Mean mitral cell numbers for these three age groups were 50,935,32,718, and 14,501, respectively. Other cell types were not enumerated. As would be expected from the work of Smith (1942), the glomerular layer was markedly influenced by age and, in the older specimens, was discontinuous and evident only in the rostral areas of the bulb.

Some studies have noted, in brains from non-demented older persons, neurofibrillary tangles in the olfactory bulb that increase as a function of age. For example, Kishikawa et al. (1990) observed such tangles in $35.3 \%$ of olfactory bulbs from 133 individuals ranging from 40 to 91 years (mean $=64.3$ years), only one of whom had dementia. Most of the tangles were within the anterior olfactory nucleus, although a few were found in mitral and tufted cells. This percentage increased to $40.5 \%$ when only those over the age of 50 years were included in the sample. Similar types of pathology have been noted in autopsied olfactory bulbs from young persons who had lived in highly polluted regions of Mexico City, in some cases in association with nanoparticles that have entered into the bulbs via the olfactory fila (CalderonGarciduenas et al., 2010).

In the first of a series of important quantitative studies, Hinds and McNelly measured the volume of the glomerular, external plexiform, internal plexiform, and olfactory nerve layers of the olfactory bulb of Sprague Dawley rats at 3, 12, 24, 27, and 30 months of age (Hinds and McNelly, 1977). They also assessed the number of mitral cells and the volume of their nuclei, cell bodies, and dendritic trees, as well as the total length and mean cross-sectional area of the associated dendrites. Until the age of 24 months, a 50\% developmental increase in the volumes of each of the layers was observed, as was a doubling in the size of the volumes of the cell bodies and dendritic trees of the mitral cells. From 24 to 30 months, the volume of olfactory bulb layers decreased. Subsequently, the number of mitral cells also decreased. Although the total volume of mitral cell dendritic trees 
declined slightly from 24 to 27 months, the volume of individual mitral cell dendritic trees, as well as cell body and nuclear size, increased, presumably reflecting compensation for the decrease in mitral cell numbers.

In a subsequent study, these general findings were replicated in the Charles River rat strain (Hinds and McNelly, 1981), save for a lack of a decline in mitral cell number in the older animals. Concurrent assessment was also made of alterations in the olfactory epithelium. After 18 months, olfactory bulb volumes declined and, after 24 months, decreases in the average volumes of the mitral cell bodies and the glomerular dendrites were observed. A comparison of regression lines for changes in number of olfactory receptors on the septum with that of the size of mitral cell bodies suggested that the decline in receptor number began several months before the decline in mitral cell size. This implied that the bulbar changes were in response to the epithelial changes. In the remaining olfactory receptor cells, an increase in the number of synapses per cell within the glomeruli occurred in the oldest rats evaluated, implying compensatory responses.

Age-related changes in the volume of human olfactory bulbs have also been documented in vivo using magnetic resonance imaging (MRI) (Yousem et al., 1998; Buschhuter et al., 2008). However, such decrements are not specific to aging, are variable, and are plastic to some degree. Thus, olfactory bulb volume is reduced in cigarette smokers (Schriever et al., 2013) and in those with a number of neurological diseases or other disorders (Yousem et al., 1995b). These include acute depression (Negoias et al., 2010), Alzheimer's disease (Thomann et al., 2009), childhood abuse (Croy et al., 2013), chronic sinusitis (Rombaux et al., 2008), congential anosmia with and without Kallmann syndrome (Yousem et al., 1993, 1996; Abolmaali et al., 2002; KoenigkamSantos et al., 2011; Levy et al., 2013), epilepsy (Hummel et al., 2012), head trauma (Yousem et al., 1995a; Doty et al., 1997; Landis et al., 2005; Jiang et al., 2009), multiple sclerosis (Goektas et al., 2011; Schmidt et al., 2011), Parkinson's disease (Wang et al., 2011b; Brodoehl et al., 2012), polyposis (Herzallah et al., 2013), schizophrenia (Turetsky et al., 2003; Nguyen et al., 2011), and prior upper respiratory infections associated with chronic smell loss (Rombaux et al., 2009). Such studies strongly suggest that olfactory bulb volume is a marker for olfactory function in general (Yousem et al., 1998; Turetsky et al., 2003; Buschhuter et al., 2008; Haehner et al., 2008; Hummel et al., 2011; Rombaux et al., 2012). Evidence of plasticity comes from observations that over time the shrinkage of olfactory bulbs in humans due to rhinosinusitis can be reversed as a result of treatment (Gudziol et al., 2009) and that rodent intrabulbar circuitry can recover from occlusion after reinstating nasal patency (Cummings and Belluscio, 2010).

\section{CHANGES IN CENTRAL BRAIN REGIONS INVOLVED IN OLFACTORY PROCESSING}

It is widely appreciated that aging is accompanied by decreased brain weight, cortical thickness, white matter integrity, and transmitter activity, and increased neuronal vulnerability, including early changes within brain structures associated with olfactory system processing (Kemper, 1984). Among such changes are disproportionate decrements in the volume of the hippocampus, amygdala, piriform cortex, anterior olfactory nucleus, and frontal poles of the brain. In a cohort of non-demented subjects ranging in age from 51 to 77 years, Segura et al. (2013) found that UPSIT scores were significantly correlated with the volume of the right amygdala and bilaterally with the volume of gray matter in the perirhinal and entorhinal cortices. Such scores were also inversely correlated with cortical thickness in the postcentral gyrus and with fractional anisotropy and mean diffusivity levels in the splenum of the corpus callosum and the superior longitudinal fasciculi.

A number of age-related neurodegenerative disease pathologies, including abnormal deposits of tau and $\alpha$-synuclein, have been associated with olfactory dysfunction in older nondemented persons, suggesting that some age-related alterations may reflect "pre-clinical" neurodegenerative disease. For example, in a longitudinal clinicopathological study of 122 non-demented subjects, Wilson et al. (2007a) found inverse correlations between B-SIT scores obtained before death and the post-mortem density of neurofibrillary tangles in the entorhinal cortex, the CA1 subfield of the hippocampus, and the subiculum. Similar associations were found by this group between pre-mortem B-SIT scores and post-mortem measures of Lewy bodies within limbic and cortical brain regions (Wilson et al., 2011b), leading the authors to conclude that olfactory function is impaired in Lewy body disease even in otherwise asymptomatic individuals.

Persons with mild cognitive impairment (MCI) who convert to $\mathrm{AD}$ typically have more smell loss than MCI patients who do not convert (Croy et al., 2009). In AD, tau-related neurofibrillary pathology seems to be more closely linked to olfactory dysfunction than $\beta$-amyloid plaque pathology. Thus, some studies find no direct associations between the AD-related decrement in odor identification ability and brain $\beta$-amyloid, as measured by PET imaging of Pittsburgh compound $\mathrm{B}$, an in vivo marker of brain amyloid levels (Bahar-Fuchs et al., 2010). This observation is consistent with post-mortem studies which, after controlling for the adverse influences of tau, find no strong associations between pre-mortem olfactory function and post-mortem levels of $\beta$-amyloid in olfactory eloquent brain regions of older individuals (Wilson et al., 2007a). It is noteworthy that anosmia, per $s e$, is correlated with wide spread changes in gray matter within olfaction-related structures, including the piriform cortex, insular cortex, OFC, medial prefrontal cortex, hippocampus, parahippocampal gyrus, supramarginal gyrus, nucleus accumbens, subcallosal gyrus, and the medial and dorsolateral prefrontal cortices (Bitter et al., 2010).

Functional imaging studies, such as those employing fMRI and positron emission tomography (PET), also demonstrate agerelated changes in the processing of olfactory information, as reflected by decrements in odor-induced activation in central olfactory pathways. It should be noted, however, that such decrements need not be indicative of the locus of dysfunction. This is because the activity of a given central brain region often depends upon input from other brain regions that themselves may be compromised. Nevertheless, such imaging does represent the overall functioning of the system. Yousem et al., in a pioneering fMRI study, found that odors activated fewer voxels within the right 

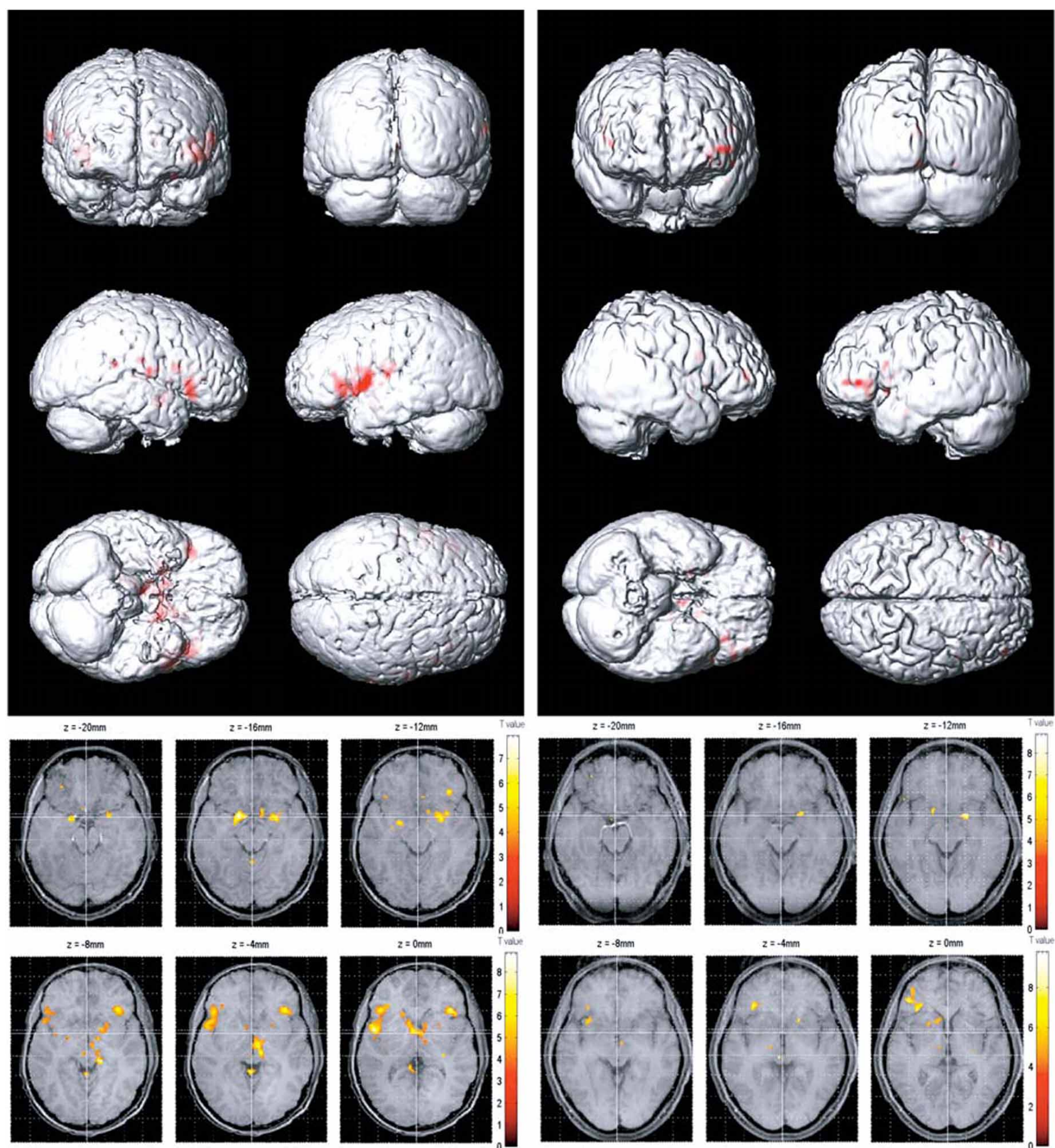

$2=.8 \mathrm{~mm}$
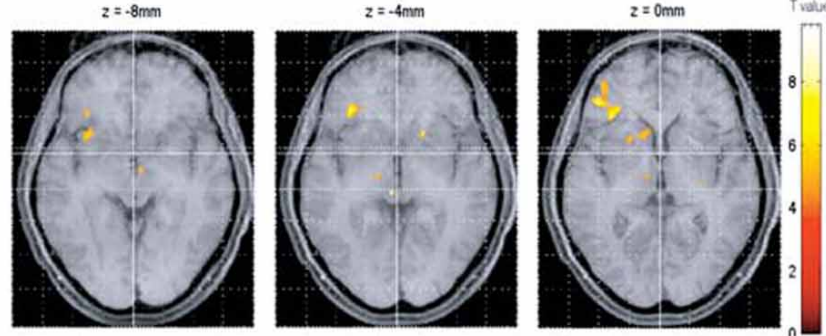

$$
\text { Young }(\mathrm{n}=11)
$$

Aged $(\mathrm{n}=8)$

FIGURE 13 | Olfactory functional magnetic resonance imaging (fMRI) activation maps from 11 younger (left; mean age $=23.9$ years) and 8 older (right; mean age $=\mathbf{6 6 . 4}$ years) persons to lavender and

inferior frontal and left and right superior frontal and perisylvian zones in old than in young persons (Yousem et al., 1999). Subsequently, Suzuki and his associates noted less fMRI odorinduced activation in 6 older persons than in 6 younger persons

spearmint odors. Note greater activation in the younger subjects. From Wang et al. (2005), with permission. Copyright@2005, Gerontological Society of America.

during an odor discrimination task in a region within the left orbital pole (Suzuki et al., 2001). Wang et al. (2005) found age-related decreases in activation in structures comprising the primary olfactory cortex, most notably in the right amygdala and 
piriform and periamygdaloid cortices (Figure 13). These investigators chose subjects whose UPSIT scores were within the normal age-adjusted range, although slightly lower scores were evident in the 11 young subjects (mean age $=23.9$ ) than in the 8 older subjects (mean age $=66.4$ ); respective UPSIT means $=37.3$ and 34.1, $p=0.0004$. More recently, Wong et al. (2010) found that a measure of nigrostriatal denervation in healthy elderly persons over the age 60 years, as determined by PET imaging of the brain dopamine transporter (DAT), was significantly correlated with UPSIT scores, suggesting that age-related declines in nigrostriatal function may account, in part, for age-related losses in smell ability.

\section{NEUROCHEMICAL CHANGES IN THE BRAIN}

It is well established that age-related changes occur in numerous enzyme, neurotransmitter, and neuromodulator systems within the brain. In many cases, the largest age-related decline occurs before the age of 60 years, as exemplified by enzymes involved in the synthesis of GABA (glutamate decarboxylase), acetylcholine (choline acetyltransferase), and both norepinephrine and dopamine (tyrosine hydroxylase) (Selkoe and Kosik, 1984). Hence, significant neurochemical changes are likely present prior to the onset of neuropathology and cognitive and motor phenotypes associated such age-related diseases as $\mathrm{AD}$ and $\mathrm{PD}$. This implies that some such changes may "prime" the organism or lower the threshold for adverse influences from neural insults, mutations, and other deleterious factors in the elderly and could be, in fact, a critical substrate for the so-called "preclinical" stages of some age-related neurodegenerative diseases. Importantly, such neurochemical changes may be region specific, preferentially involving, for example, limbic structures early in the aging process (Strong, 1998). Imaging studies suggest that binding sites for a number of neurotransmitters are significantly decreased in the brains of older persons (Dewey et al., 1990; Rosier et al., 1996; Volkow et al., 2000).

While several age-related neurotransmitter deficiencies may contribute to the olfactory loss observed in elderly persons, one system stands out as being particularly prepotent-the cholinergic system. Acetylcholine is intimately involved in the modulation of olfactory function, such as increasing contrast and synchronization of odor-induced activity from the bulb to the piriform cortex and facilitating attention, odor learning, memory, and cortical plasticity (de Almeida et al., 2013). Cholinergic projections reach all sectors of the olfactory system from origins within the medial septum, the nucleus basalis of Meynert, and the horizontal and vertical diagonal band of Broca (Schliebs and Arendt, 2011). Patients with MCI exhibit olfactory deficits and cholinergic dysfunction prior to the onset of $\mathrm{AD}-$ dysfunction which is unaccompanied by significant cell loss (Schliebs and Arendt, 2011). Interestingly, cholinergic neurons directly modulate neural activity within the olfactory bulb and tonically inhibit, along with some other neurotransmitters, the activity of microglial cells critical for immune responses to brain damage and foreign agents (Doty, 2012a). When such modulation is significantly perturbed, the release of inhibition on the microglial cells can occur, resulting in the secretion of inflammatory mediators and other factors which, in extreme instances, can be deleterious to neurons (Tang et al., 2007; Lalancette-Hebert et al., 2009).

It is noteworthy that the relative magnitude of olfactory deficits of a number of neurodegenerative and neurodevelopmental diseases appears to be associated with the relative damage to the basal cholinergic system. Such disorders include AD, PD, Down syndrome, Parkinson-Dementia complex of Guam, Korsakoff syndrome, amyotrophic lateral sclerosis, schizophrenia, and progressive supranuclear palsy (for olfactory test scores, see, e.g., Mair et al., 1986; Doty et al., 1987, 1988, 1991, 1993; Kopala et al., 1994; Sajjadian et al., 1994; Wenning et al., 1995; McKeown et al., 1996; for quantitative assessments of basal cholinergic cell losses or volumes, see Arendt et al., 1983; Nakano and Hirano, 1983, 1984; Casanova et al., 1985; Rogers et al., 1985; Vogels et al., 1990; Yoshida et al., 1992; Kasashima and Oda, 2003). Age-related damage to the nucleus basalis has also been observed, although its magnitude is not generally as marked as that seen in $\mathrm{AD}$ and $\mathrm{PD}$.

\section{CONCLUSION}

This review addressed the functional and pathophysiological changes that occur in the human olfactory system as a result of age. Basic information about the anatomy, physiology, and measurement of this primary sensory system was provided, along with a general overview of the nature of age-related changes that occur in olfactory perception. Numerous factors that likely contribute to such changes were assessed, including changes in autonomic control of nasal engorgement, increased propensity for nasal disease, cumulative damage to the olfactory epithelium from environmental insults, decrements in protective metabolizing enzymes in the olfactory mucosa, occlusion of the foramina of the cribriform plate, loss of selectivity of olfactory receptor neurons to odorants, changes in neurotransmitter and neuromodulator systems, and neuropathological processes such as the expression of aberrant proteins associated with such neurodegenerative diseases as $\mathrm{AD}$ and $\mathrm{PD}$. As apparent from the research examined in this review, it is likely that there are multiple determinants of the olfactory loss of older persons, although the relative importance of each is yet to be established.

\section{AUTHOR CONTRIBUTIONS}

Dr. Doty wrote the first draft of the manuscript. Dr. Kamath contributed to the literature review and to the writing of two subsequent drafts. Both authors were involved in the writing of the final manuscript.

\section{ACKNOWLEDGMENTS}

This research was supported by the following contract: DOD W81XWH-09-1-0467.

\section{REFERENCES}

Abolmaali, N. D., Hietschold, V., Vogl, T. J., Huttenbrink, K. B., and Hummel, T. (2002). MR evaluation in patients with isolated anosmia since birth or early childhood. Am. J. Neuroradiol. 23, 157-164.

Allen, W. F. (1928). Effect on respiration, blood pressure, and carotid pulse of various inhaled and insufflated vapors when stimulating one cranial nerve and various combinations of cranial nerves. Amer. J. Physiol. 87, 319-325.

Arendt, T., Bigl, V., Arendt, A., and Tennstedt, A. (1983). Loss of neurons in the nucleus basalis of Meynert in Alzheimer's disease, paralysis agitans and Korsakoff's disease. Acta Neuropathol. 61, 101-108. doi: 10.1007/BF00697388 
Bahar-Fuchs, A., Chetelat, G., Villemagne, V. L., Moss, S., Pike, K., Masters, C. L., et al. (2010). Olfactory deficits and amyloid-beta burden in Alzheimer's disease, mild cognitive impairment, and healthy aging: a PiB PET study. J. Alzheimers. Dis. 22, 1081-1087.

Barresi, M., Ciurleo, R., Giacoppo, S., Foti, C. V., Celi, D., Bramanti, P., et al. (2012). Evaluation of olfactory dysfunction in neurodegenerative diseases. J. Neurol. Sci. 323, 16-24. doi: 10.1016/j.jns.2012.08.028

Bedard, A., and Parent, A. (2004). Evidence of newly generated neurons in the human olfactory bulb. Dev. Brain Res. 151, 159-168. doi: 10.1016/j.devbrainres.2004.03.021

Bende, M. (1983). Blood flow with 133 Xe in human nasal mucosa in relation to age, sex and body position. Acta Otolaryngol. 96, 175-179. doi: 10.3109/00016488309132889

Bensafi, M., Rouby, C., Farget, V., Bertrand, B., Vigouroux, M., and Holley, A. (2002). Influence of affective and cognitive judgments on autonomic parameters during inhalation of pleasant and unpleasant odors in humans. Neurosci. Lett. 319, 162-166. doi: 10.1016/S0304-3940(01)02572-1

Bhandawat, V., Reisert, J., and Yau, K. W. (2005). Elementary response of olfactory receptor neurons to odorants. Science 308, 1931-1934. doi: 10.1126/science. 1109886

Bhatnagar, K. P., Kennedy, R. C., Baron, G., and Greenberg, R. A. (1987). Number of mitral cells and the bulb volume in the aging human olfactory bulb: a quantitative morphological study. Anat. Rec. 218, 73-87. doi: 10.1002/ar. 1092180112

Bitter, T., Gudziol, H., Burmeister, H. P., Mentzel, H. J., Guntinas-Lichius, O., and Gaser, C. (2010). Anosmia leads to a loss of gray matter in cortical brain areas. Chem. Senses 35, 407-415. doi: 10.1093/chemse/bjq028

Borders, A. S., Hersh, M. A., Getchell, M. L., van, R. N., Cohen, D. A., Stromberg, A. J., et al. (2007). Macrophage-mediated neuroprotection and neurogenesis in the olfactory epithelium. Physiol. Genomics 31, 531-543. doi: 10.1152/physiolgenomics.00008.2007

Bramerson, A., Johansson, L., Ek, L., Nordin, S., and Bende, M. (2004). Prevalence of olfactory dysfunction: the skovde population-based study. Laryngoscope 114, 733-737. doi: 10.1097/00005537-200404000-00026

Breer, H. (1994). Odor recognition and second messenger signaling in olfactory receptor neurons. Sem. Cell Biol. 5, 25-32. doi: 10.1006/scel.1994.1004

Brodoehl, S., Klingner, C., Volk, G. F., Bitter, T., Witte, O. W., and Redecker, C. (2012). Decreased olfactory bulb volume in idiopathic Parkinson's disease detected by 3.0-Tesla magnetic resonance imaging. Mov. Disord. 27, 1019-1025. doi: $10.1002 / \mathrm{mds} .25087$

Bromley, S. M., and Doty, R. L. (1995). Odor recognition memory is better under bilateral than unilateral test conditions. Cortex 31, 25-40. doi: 10.1016/S00109452(13)80103-7

Buschhuter, D., Smitka, M., Puschmann, S., Gerber, J. C., Witt, M., Abolmaali, N. D., et al. (2008). Correlation between olfactory bulb volume and olfactory function. Neuroimage 42, 498-502. doi: 10.1016/j.neuroimage.2008.05.004

Cain, W. S., Gent, J., Catalanotto, F. A., and Goodspeed, R. B. (1983). Clinical evaluation of olfaction. Am. J. Otolaryngol. 4, 252-256. doi: 10.1016/S01960709(83)80068-4

Cain, W. S., and Gent, J. F. (1991). Olfactory sensitivity: reliability, generality, and association with aging. J. Exp. Psychol. Hum Percept. Perform. 7, 382-391. doi: 10.1037/0096-1523.17.2.382

Cain, W. S., and Stevens, J. C. (1989). Uniformity of olfactory loss in aging. Ann. N.Y. Acad. Sci. 561, 29-38. doi: 10.1111/j.1749-6632.1989.tb20967.x

Calderon-Garciduenas, L., Franco-Lira, M., Henriquez-Roldan, C., Osnaya, N., Gonzalez-Maciel, A., Reynoso-Robles, R., et al. (2010). Urban air pollution: influences on olfactory function and pathology in exposed children and young adults. Exp. Tox. Pathol. 62, 91-102. doi: 10.1016/j.etp.2009.02.117

Calhoun-Haney, R., and Murphy, C. (2005). Apolipoprotein epsilon4 is associated with more rapid decline in odor identification than in odor threshold or dementia rating scale scores. Brain Cogn. 58, 178-182. doi: 10.1016/j.bandc.2004.10.004

Camara, C. G., and Harding, J. W. (1984). Thymidine incorporation in the olfactory epithelium of mice: early exponential response induced by olfactory neurectomy. Brain Res. 308, 63-68. doi: 10.1016/0006-8993(84) 90917-X

Cameron, E. L., and Doty, R. L. (2013). Odor identification testing in children and young adults using the smell wheel. Int. J. Pediatr. Otorhinolaryngol. 77, 346-350. doi: 10.1016/j.ijporl.2012.11.022
Casanova, M. F., Walker, L. C., Whitehouse, P. J., and Price, D. L. (1985). Abnormalities of the nucleus basalis in Down's syndrome. Ann. Neurol. 18, 310-313. doi: 10.1002/ana.410180306

Chalke, H. D., Dewhurst, J. R., and Ward, C. W. (1958). Loss of smell in old people. Public Health 72, 223-230. doi: 10.1016/S0033-3506(58)80053-0

Chess, A., Simon, I., Cedar, H., and Axel, R. (1994). Allelic inactivation regulates olfactory receptor gene expression. Cell 78, 823-834. doi: 10.1016/S00928674(94)90562-2

Cho, S. H., Hong, S. J., Han, B., Lee, S. H., Suh, L., Norton, J., et al. (2012). Agerelated differences in the pathogenesis of chronic rhinosinusitis. J. Allergy Clin. Immunol. 129, 858-860. doi: 10.1016/j.jaci.2011.12.002

Choudhury, E. S., Moberg, P., and Doty, R. L. (2003). Influences of age and sex on a microencapsulated odor memory test. Chem. Senses 28, 799-805. doi: 10.1093/chemse/bjg072

Cleland, T. A., and Linster, C. (2003). "Central olfactory structures," in Handbook of Olfaction and Gustation. 2nd Edn., ed R. L. Doty (New York, NY: Marcel Dekker), 165-180.

Cohen, N. A. (2006). Sinonasal mucociliary clearance in health and disease. Ann. Otol. Rhinol. Laryngol. Suppl 196, 20-26.

Conti, M. Z., Vicini-Chilovi, B., Riva, M., Zanetti, M., Liberini, P., Padovani, A., et al. (2013). Odor identification deficit predicts clinical conversion from mild cognitive impairment to dementia due to Alzheimer's disease. Arch. Clin. Neuropsychol. 28, 391-399. doi: 10.1093/arclin/act032

Covington, J. W., Geisler, M. W., Polich, J., and Murphy, C. (1999). Normal aging and odor intensity effects on the olfactory event-related potential. Int. J Psychophysiol. 32, 205-214. doi: 10.1016/S0167-8760(99)00012-4

Cowart, B. J. (1989). Relationships between taste and smell across the adult life span. Ann. N.Y. Acad. Sci. 561, 39-55. doi: 10.1111/j.1749-6632.1989. tb20968.x

Croy, I., Lange, K., Krone, F., Negoias, S., Seo, H. S., and Hummel, T. (2009). Comparison between odor thresholds for phenyl ethyl alcohol and butanol. Chem. Senses. 34, 523-527. doi: 10.1093/chemse/bjp029

Croy, I., Negoias, S., Symmank, A., Schellong, J., Joraschky, P., and Hummel, T. (2013). Reduced olfactory bulb volume in adults with a history of childhood maltreatment. Chem. Senses 38, 679-684. doi: 10.1093/chemse/bjt037

Cummings, D. M., and Belluscio, L. (2010). Continuous neural plasticity in the olfactory intrabulbar circuitry. J. Neurosci. 30, 9172-9180. doi: 10.1523/JNEUROSCI.1717-10.2010

de Almeida, L., Idiart, M., and Linster, C. (2013). A model of cholinergic modulation in olfactory bulb and piriform cortex. J. Neurophysiol. 109, 1360-1377. doi: 10.1152/jn.00577.2012

Deems, D. A., and Doty, R. L. (1987). Age-related changes in the phenyl ethyl alcohol odor detection threshold. Trans. Pa. Acad. Ophthalmol. Otolaryngol. 39, 646-650.

De Lorenzo, A. J. (1957). Electron microscopic observations of the olfactory mucosa and olfactory nerve. J. Biophys. Biochem. Cytol. 3, 839-850. doi: 10.1083/jcb.3.6.839

Devanand, D. P., Michaels-Marston, K. S., Liu, X., Pelton, G. H., Padilla, M., Marder, K., et al. (2000). Olfactory deficits in patients with mild cognitive impairment predict Alzheimer's disease at follow-up. Am. J. Psychiatry 157, 1399-1405. doi: 10.1176/appi.ajp.157.9.1399

Dewey, S. L., Volkow, N. D., Logan, J., MacGregor, R. R., Fowler, J. S., Schlyer, D. J., et al. (1990). Age-related decreases in muscarinic cholinergic receptor binding in the human brain measured with positron emission tomography (PET). J. Neurosci. Res. 27, 569-575. doi: 10.1002/jnr.490270418

Ding, X., and Dahl, A. R. (2003). "Olfactory mucosa: composition, enzymatic localization, and metabolism," in Handbook of Olfaction and Gustation. 2nd Edn., ed R. L. Doty (New York, NY: Marcel Dekker), 51-73.

Doty, R. L. (1995). The Smell Identification TestTM Administration Manual. 3rd Edn. Haddon Heights, NJ: Sensonics, Inc.

Doty, R. L. (2012a). Olfaction in Parkinson's disease and related disorders. Neurobiol. Dis. 46, 527-552. doi: 10.1016/j.nbd.2011.10.026

Doty, R. L. (2012b). Olfactory dysfunction in Parkinson disease. Nat. Rev. Neurol. 8, 329-339. doi: 10.1038/nrneurol.2012.80

Doty, R. L., Deems, D. A., and Stellar, S. (1988). Olfactory dysfunction in parkinsonism: a general deficit unrelated to neurologic signs, disease stage, or disease duration. Neurology 38, 1237-1244. doi: 10.1212/WNL.38.8.1237

Doty, R. L., Golbe, L. I., McKeown, D. A., Stern, M. B., Lehrach, C. M., and Crawford, D. (1993). Olfactory testing differentiates between progressive 
supranuclear palsy and idiopathic Parkinson's disease. Neurology 43, 962-965. doi: 10.1212/WNL.43.5.962

Doty, R. L., and Laing, D. A. (2003). "Psychophysical measurement of human olfactory function, including odorant mixture assessment," in Handbook of Olfaction and Gustation. 2nd Edn., ed R. L. Doty (New York, NY: Marcel Dekker), 203-228. doi: 10.1201/9780203911457

Doty, R. L., Marcus, A., and Lee, W. W. (1996). Development of the 12 -item crosscultural smell identification test (CC-SIT). Laryngoscope 106, 353-356. doi: 10.1097/00005537-199603000-00021

Doty, R. L., McKeown, D. A., Lee, W. W., and Shaman, P. (1995). A study of the test-retest reliability of ten olfactory tests. Chem. Senses 20, 645-656. doi: 10.1093/chemse/20.6.645

Doty, R. L., Perl, D. P., Steele, J. C., Chen, K. M., Pierce, J. D. Jr., Reyes, P., et al. (1991). Odor identification deficit of the parkinsonism-dementia complex of Guam: equivalence to that of Alzheimer's and idiopathic Parkinson's disease. Neurology 41, 77-80. doi: 10.1212/WNL.41.5_Suppl_2.77

Doty, R. L., Petersen, I., Mensah, N., and Christensen, K. (2011). Genetic and environmental influences on odor identification ability in the very old. Psychol. Aging 26, 864-871. doi: 10.1037/a0023263

Doty, R. L., Reyes, P. F., and Gregor, T. (1987). Presence of both odor identification and detection deficits in Alzheimer's disease. Brain Res. Bull. 18, 597-600. doi: 10.1016/0361-9230(87)90129-8

Doty, R. L., Shaman, P., Applebaum, S. L., Giberson, R., Siksorski, L., and Rosenberg, L. (1984a). Smell identification ability: changes with age. Science 226, 1441-1443. doi: 10.1126/science.6505700

Doty, R. L., Shaman, P., and Dann, M. (1984b). Development of the University of Pennsylvania smell identification test: a standardized microencapsulated test of olfactory function. Physiol. Behav. 32, 489-502. doi: 10.1016/00319384(84)90269-5

Doty, R. L., Smith, R., McKeown, D. A., and Raj, J. (1994). Tests of human olfactory function: principal components analysis suggests that most measure a common source of variance. Percept. Psychophys. 56, 701-707. doi: 10.3758/BF03208363

Doty, R. L., Yousem, D. M., Pham, L. T., Kreshak, A. A., Geckle, R., and Lee, W. W. (1997). Olfactory dysfunction in patients with head trauma. Arch. Neurol. 54, 1131-1140. doi: 10.1001/archneur.1997.00550210061014

Duda, J. E. (2010). Olfactory system pathology as a model of Lewy neurodegenerative disease. J. Neurol. Sci. 289, 49-54. doi: 10.1016/j.jns.2009.08.042

Duffy, V. B., Backstrand, J. R., and Ferris, A. M. (1995). Olfactory dysfunction and related nutritional risk in free-living, elderly women. J. Am. Diet. Assoc. 8, 879-884. doi: 10.1016/S0002-8223(95)00244-8

Edelstein, D. R. (1996). Aging of the normal nose in adults. Laryngoscope 106, 1-25. doi: 10.1097/00005537-199609001-00001

Engen, T., Kuisma, J. E., and Eimas, P. D. (1973). Short-term memory of odors. J. Exp. Psychol. 99, 222-225. doi: 10.1037/h0034645

Evans, W. J., Cui, L., and Starr, A. (1995). Olfactory event-related potentials in normal human subjects: effects of age and gender. EEG Clin. Neurophysiol. 95, 293-301. doi: 10.1016/0013-4694(95)00055-4

Farajnia, S., Deboer, T., Rohling, J. H., Meijer, J. H., and Michel, S. (2014). Aging of the suprachiasmatic clock. Neuroscientist 20, 44-55. doi: 10.1177/1073858413 498936

Federico, G., Maremmani, C., Cinquanta, L., Baroncelli, G. I., Fattori, B., and Saggese, G. (1999). Mucus of the human olfactory epithelium contains the insulin-like growth factor-I system which is altered in some neurodegenerative diseases. Brain Res. 835, 306-314. doi: 10.1016/S0006-8993(99)01614-5

Feron, F., Mackay-Sim, A., Andrieu, J. L., Matthaei, K. I., Holley, A., and Sicard, G. (1999). Stress induces neurogenesis in non-neuronal cell cultures of adult olfactory epithelium. Neuroscience. 88, 571-583. doi: 10.1016/S0306$4522(98) 00233-4$

Fordyce, I. D. (1961). Olfaction tests. Br. J. Ind. Med. 18, 213-215.

Frank, R. A., Dulay, M. F., and Gesteland, R. C. (2003). Assessment of the sniff magnitude test as a clinical test of olfactory function. Physiol. Behav. 78, 195-204. doi: 10.1016/S0031-9384(02)00965-4

Frank, R. A., Dulay, M. F., Niergarth, K. A., and Gesteland, R. C. (2004). A comparison of the sniff magnitude test and the University of Pennsylvania smell identification test in children and nonnative english speakers. Physiol. Behav. 81, 475-480. doi: 10.1016/j.physbeh.2004.02.020

Frank, R. A., Gesteland, R. C., Bailie, J., Rybalsky, K., Seiden, A., and Dulay, M. F. (2006). Characterization of the sniff magnitude test. Arch. Otolaryngol. Head Neck Surg. 132, 532-536. doi: 10.1001/archotol.132.5.532
Frühwald, V. (1935). Die Folgen des einseitigen Nasenverschlusses auf die Riechschleimhaut und auf den Bulbus und Tractus olfactorius. Archiv. fur Ohren Nasen und Kehlkopfheilkunde 139, 153-173. doi: 10.1007/BF01586653

Frye, R. E. (2003). "Nasal patency and the aerodynamics of nasal airflow: measurement by rhinomanometry and acoustic rhinometry, and the influence of pharmacological agents," in Handbook of Olfaction and Gustation. 2nd Edn., ed R. L. Doty (New York, NY: Marcel Dekker), 439-460.

Frye, R. E., and Doty, R. L. (1992). Chemical Signals in Vertebrates, Vol. VI, eds R. L. Doty and D. Müller-Schwarze. (New York, NY: Plenum), 595-596. doi: 10.1007/978-1-4757-9655-1_91

Gaskell, B. A., Hext, P. M., Pigott, G. H., Doe, J. E., and Hodge, M. C. (1990). Olfactory and hepatic changes following a single inhalation exposure of 3trifluoromethyl pyridine in rats: concentration and temporal aspects. Toxicology 62, 35-51. doi: 10.1016/0300-483X(90)90029-G

Getchell, M. L., and Getchell, T. V. (1992). Fine structural aspects of secretion and extrinsic innervation in the olfactory mucosa. Microsc. Res. Tech. 23, 111-127. doi: 10.1002/jemt.1070230203

Getchell, T. V., Krishna, N. S., Dhooper, N., Sparks, D. L., and Getchell, M. L. (1995). Human olfactory receptor neurons express heat shock protein 70: age-related trends. Ann. Otol. Rhinol. Laryngol. 104, 47-56.

Gevins, A. S., and Remond, A. (1987). Methods of Analysis of Brain Electrical and Magnetic Signals. New York, NY: Elsevier.

Gilbert, A. N. (1989). Reciprocity versus rhythmicity in spontaneous alternations of nasal airflow. Chronobiol. Int. 6, 251-257. doi: 10.3109/07420528909056926

Gladysheva, O., Kukushkina, D., and Martynova, G. (1986). Glycoprotein composition of olfactory mucus in vertebrates. Acta Histochem. 78, 141-146. doi: 10.1016/S0065-1281(86)80047-2

Glusman, G., Yanai, I., Rubin, I., and Lancet, D. (2001). The complete human olfactory subgenome. Genome Res. 11, 685-702. doi: 10.1101/gr.171001

Goektas, O., Schmidt, F., Bohner, G., Erb, K., Ludemann, L., Dahlslett, B., et al. (2011). Olfactory bulb volume and olfactory function in patients with multiple sclerosis. Rhinology 49, 221-226. doi: 10.4193/Rhino10.136

Graves, A. B., Bowen, J. D., Rajaram, L., McCormick, W. C., McCurry, S. M., Schellenberg, G. D., et al. (1999). Impaired olfaction as a marker for cognitive decline: interaction with apolipoprotein E epsilon4 status. Neurology 53, 1480-1487. doi: 10.1212/WNL.53.7.1480

Griep, M. I., Mets, T. F., Collys, K., Vogelaere, P., Laska, M., and Massart, D. L. (1997). Odour perception in relation to age, general health, anthropometry and dental state. Arch. Gerontol. Geriatr. 25, 263-275. doi: 10.1016/S01674943(97)00017-4

Gudziol, V., Buschhuter, D., Abolmaali, N., Gerber, J., Rombaux, P., and Hummel, T. (2009). Increasing olfactory bulb volume due to treatment of chronic rhinosinusitis-a longitudinal study. Brain 132, 3096-3101. doi: 10.1093/brain/awp243

Haehner, A., Rodewald, A., Gerber, J. C., and Hummel, T. (2008). Correlation of olfactory function with changes in the volume of the human olfactory bulb. Arch. Otolaryngol. Head Neck Surg. 134, 621-624. doi: 10.1001/archotol.134. 6.621

Harkema, J. R., Carey, S. A., and Wagner, J. G. (2006). The nose revisited: a brief review of the comparative structure, function, and toxicologic pathology of the nasal epithelium. Toxicol. Pathol. 34, 252-269. doi: 10.1080/01926230600713475

Hedner, M., Larsson, M., Arnold, N., Zucco, G. M., and Hummel, T. (2010a). Cognitive factors in odor detection, odor discrimination, and odor identification tasks. J. Clin. Exp. Neuropsychol. 32, 1062-1067. doi: 10.1080/1380339100 3683070

Hedner, M., Nilsson, L. G., Olofsson, J. K., Bergman, O., Eriksson, E., Nyberg, L., et al. (2010b). Age-related olfactory decline is associated with the BDNF Val66met polymorphism: evidence from a population-based study. Front. Aging Neurosci. 2:24. doi: 10.3389/fnagi.2010.00024

Herting, B., Schulze, S., Reichmann, H., Haehner, A., and Hummel, T. (2008). A longitudinal study of olfactory function in patients with idiopathic Parkinson's disease. J. Neurol. 255, 367-370. doi: 10.1007/s00415-008-0665-5

Herzallah, I. R., Askar, S. M., Amer, H. S., Ahmed, A. F., El-Anwar, M. W., and Eesa, M. H. (2013). Olfactory bulb volume changes in patients with sinonasal polyposis: a magnetic resonance imaging study. Otolaryngol. Head Neck Surg. 148, 689-693. doi: 10.1177/0194599813477606

Hinds, J. W., and McNelly, N. A. (1977). Aging of the rat olfactory bulb: growth and atrophy of constituent layers and changes in size and number of mitral cells. J. Comp. Neurol. 72, 345-367. doi: 10.1002/cne.901710304 
Hinds, J. W., and McNelly, N. A. (1981). Aging in the rat olfactory system: correlation of changes in the olfactory epithelium and olfactory bulb. J. Comp. Neurol. 203, 441-453. doi: 10.1002/cne.902030308

Hirai, T., Kojima, S., Shimada, A., Umemura, T., Sakai, M., and Itakura, C. (1996). Age-related changes in the olfactory system of dogs. Neuropathol. Appl. Neurobiol. 22, 531-539. doi: 10.1111/j.1365-2990.1996.tb01132.x

Holley, A., Duchamp, A., Revial, M. F., and Juge, A. (1974). Qualitative and quantitative discrimination in the frog olfactory receptors: analysis from electrophysiological data. Ann. N.Y. Acad. Sci. 237, 102-128. doi: 10.1111/j.17496632.1974.tb49847.x

Holt, C. M. (1917). Studies on the olfactory bulbs of the albino rat. I. Experiments to determine the effect of a defective diet and of exercise upon the weight of the olfactory bulbs. J. Comp. Neurol. 27, 201-234. doi: 10.1002/cne.900270203

Hosoya, Y., and Yashida, H. (1937). Über die bioelektrische Erscheinungen an der Riechschleimhaut. Jpn. J. Med. Sci. III. Biophys. 5, 22-23.

Huart, C., Legrain, V., Hummel, T., Rombaux, P., and Mouraux, A. (2012). Timefrequency analysis of chemosensory event-related potentials to characterize the cortical representation of odors in humans. PLoS ONE 7:e33221. doi: 10.1371/journal.pone.0033221

Hummel, T., Barz, S., Pauli, E., and Kobal, G. (1998). Chemosensory event-related potentials change with age. Electroencephalogr. Clin. Neurophysiol. 108, 208-217. doi: 10.1016/S0168-5597(97)00074-9

Hummel, T., Henkel, S., Negoias, S., Galvan, J. R., Bogdanov, V., Hopp, P., et al. (2012). Olfactory bulb volume in patients with temporal lobe epilepsy. J. Neurol. 260, 1004-1008. doi: 10.1007/s00415-012-6741-x

Hummel, T., Sekinger, B., Wolf, S. R., Pauli, E., and Kobal, G. (1997). "Sniffin' sticks": olfactory performance assessed by the combined testing of odor identification, odor discrimination and olfactory threshold. Chem. Senses 22, 39-52. doi: $10.1093 /$ chemse/22.1.39

Hummel, T., Smitka, M., Puschmann, S., Gerber, J. C., Schaal, B., and Buschhuter, D. (2011). Correlation between olfactory bulb volume and olfactory function in children and adolescents. Exp. Brain Res. 214, 285-291. doi: 10.1007/s00221011-2832-7

Iranzo, A., Serradell, M., Vilaseca, I., Valldeoriola, F., Salamero, M., Molina, C., et al. (2013). Longitudinal assessment of olfactory function in idiopathic REM sleep behavior disorder. Parkinsonism Relat. Disord. 19, 600-604. doi: 10.1016/j.parkreldis.2013.02.009

Iwai, N., Zhou, Z., Roop, D. R., and Behringer, R. R. (2008). Horizontal basal cells are multipotent progenitors in normal and injured adult olfactory epithelium. Stem Cells 26, 1298-1306. doi: 10.1634/stemcells.2007-0891

Jarvis, D., Newson, R., Lotvall, J., Hastan, D., Tomassen, P., Keil, T., et al. (2012). Asthma in adults and its association with chronic rhinosinusitis: the GA2LEN survey in Europe. Allergy 67, 91-98. doi: 10.1111/j.1398-9995.2011.02709.x

Jehl, C., Royet, J. P., and Holley, A. (1995). Odor discrimination and recognition memory as a function of familiarization. Percept. Psychophys. 57, 1002-1011. doi: 10.3758/BF03205459

Jiang, R. S., Chai, J. W., Chen, W. H., Fuh, W. B., Chiang, C. M., and Chen, C. C. (2009). Olfactory bulb volume in Taiwanese patients with posttraumatic anosmia. Am. J. Rhinol. Allergy 23, 582-584. doi: 10.2500/ajra.2009.23.3370

Johnson, B. A., and Leon, M. (2007). Chemotopic odorant coding in a mammalian olfactory system. J. Comp. Neurol. 503, 1-34. doi: 10.1002/cne.21396

Jones-Gotman, M., and Zatorre, R. J. (1988). Olfactory identification deficits in patients with focal cerebral excision. Neuropsychologia 26, 387-400. doi: 10.1016/0028-3932(88)90093-0

Jonsson, F. U., Moller, P., and Olsson, M. J. (2011). Olfactory working memory: effects of verbalization on the 2-back task. Mem. Cogn. 39, 1023-1032. doi: 10.3758/s13421-011-0080-5

Joyner, R. E. (1963). Olfactory acuity in an industrial population. J. Occup. Med. 5, 37-42.

Kajiya, K., Inaki, K., Tanaka, M., Haga, T., Kataoka, H., and Touhara, K. (2001). Molecular bases of odor discrimination: reconstitution of olfactory receptors that recognize overlapping sets of odorants. J. Neurosci. 21, 6018-6025.

Kalmey, J. K., Thewissen, J. G., and Dluzen, D. E. (1998). Age-related size reduction of foramina in the cribriform plate. Anat. Rec. 251, 326-329. doi: 10.1002/(SICI)1097-0185(199807)251:3<326::AID-AR7>3.3.CO;2-\#

Kam, M., Curtis, M. A., McGlashan, S. R., Connor, B., Nannmark, U., and Faull, R. L. (2009). The cellular composition and morphological organization of the rostral migratory stream in the adult human brain. J. Chem. Neuroanat. 37, 196-205. doi: 10.1016/j.jchemneu.2008.12.009
Kaneda, H., Maeshima, K., Goto, N., Kobayakawa, T., Ayabe-Kanamura, S., and Saito, S. (2000). Decline in taste and odor discrimination abilities with age, and relationship between gustation and olfaction. Chem. Senses 25, 331-337. doi: 10.1093/chemse/25.3.331

Karpa, M. J., Gopinath, B., Rochtchina, E., Jie, J. W., Cumming, R. G., Sue, C. M., et al. (2010). Prevalence and neurodegenerative or other associations with olfactory impairment in an older community. J. Aging Health 22, 154-168. doi: $10.1177 / 0898264309353066$

Kasashima, S., and Oda, Y. (2003). Cholinergic neuronal loss in the basal forebrain and mesopontine tegmentum of progressive supranuclear palsy and corticobasal degeneration. Acta Neuropathol. 105, 117-124. doi: 10.1007/s00401002-0621-x

Katoh, H., Shibata, S., Fukuda, K., Sato, M., Satoh, E., Nagoshi, N., et al. (2011). The dual origin of the peripheral olfactory system: placode and neural crest. Mol. Brain 4:34. doi: 10.1186/1756-6606-4-34

Kay, L. M., and Sherman, S. M. (2007). An argument for an olfactory thalamus. Trends Neurosci. 30, 47-53. doi: 10.1016/j.tins.2006.11.007

Kemper, T. (1984). "Neuroanatomical and neuropathological changes during age and dementia," in Clinical Neurology of Aging, ed M. L. Albert (New York, NY: Oxford University Press), 3-67.

Kimbrell, G. M., and Furchtgott, E. (1963). The effect of aging on olfactory threshold. J. Gerontol. 18, 364-365. doi: 10.1093/geronj/18.4.364

Kirstein, C. L., Coopersmith, R., Bridges, R. J., and Leon, M. (1991). Glutathione levels in olfactory and non-olfactory neural structures of rats. Brain Res. 543, 341-346. doi: 10.1016/0006-8993(91)90047-Y

Kishikawa, M., Iseki, M., Nishimura, M., Sekine, I., and Fujii, H. (1990). A histopathological study on senile changes in the human olfactory bulb. Acta Pathol. Jpn. 40, 255-260. doi: 10.1111/j.1440-1827.1990.tb01559.x

Kleemann, A. M., Kopietz, R., Albrecht, J., Schopf, V., Pollatos, O., Schreder, T., et al. (2009). Investigation of breathing parameters during odor perception and olfactory imagery. Chem. Senses 34, 1-9. doi: 10.1093/chemse/bjn042

Kobal, G., Hummel, T., Sekinger, B., Barz, S., Roscher, S., and Wolf, S. (1996). "Sniffin' sticks": screening of olfactory performance. Rhinology 34, 222-226.

Kobal, G., Klimek, L., Wolfensberger, M., Gudziol, H., Temmel, A., Owen, C. M., et al. (2000). Multicenter investigation of 1,036 subjects using a standardized method for the assessment of olfactory function combining tests of odor identification, odor discrimination, and olfactory thresholds. Eur. Arch. Otorhinolaryngol. 257, 205-211. doi: 10.1007/s004050050223

Kobayashi, M., Saito, S., Kobayakawa, T., Deguchi, Y., and Costanzo, R. M. (2006). Cross-cultural comparison of data using the odor stick identification test for Japanese (OSIT-J). Chem Senses 31, 335-342. doi: 10.1093/chemse/bjj037

Koenigkam-Santos, M., Santos, A. C., Versiani, B. R., Diniz, P. R., Junior, J. E., and de Castro, M. (2011). Quantitative magnetic resonance imaging evaluation of the olfactory system in Kallmann syndrome: correlation with a clinical smell test. Neuroendocrinology 94, 209-217. doi: 10.1159/000328437

Kopala, L. C., Good, K. P., and Honer, W. G. (1994). Olfactory hallucinations and olfactory identification ability in patients with schizophrenia and other psychiatric disorders. Schizophr. Res. 12, 205-211. doi: 10.1016/0920-9964(94) 90030-2

Koskinen, S., Vento, S., Malmberg, H., and Tuorila, H. (2004). Correspondence between three olfactory tests and suprathreshold odor intensity ratings. Acta Otolaryngol. (Stockh) 124, 1072-1077. doi: 10.1080/00016480410015776

Krantz, E. M., Schubert, C. R., Dalton, D. S., Zhong, W., Huang, G. H., Klein, B. E., et al. (2009). Test-retest reliability of the San Diego odor identification test and comparison with the brief smell identification test. Chem. Senses 34, 435-440. doi: 10.1093/chemse/bjp018

Krishna, N. S., Getchell, T. V., Dhooper, N., Awasthi, Y. C., and Getchell, M. L. (1995). Age- and gender-related trends in the expression of glutathione Stransferases in human nasal mucosa. Ann. Otol. Rhinol. Laryngol. 104, 812-822.

Krmpotic-Nemanic, J. (1969). Presbycusis, presbystasis and presbyosmia as consequences of the analogous biological process. Acta Otolaryngol. (Stockh) 67, 217-223. doi: 10.3109/00016486909125446

Lalancette-Hebert, M., Phaneuf, D., Soucy, G., Weng, Y. C., and Kriz, J. (2009). Live imaging of Toll-like receptor 2 response in cerebral ischaemia reveals a role of olfactory bulb microglia as modulators of inflammation. Brain 132, 940-954. doi: 10.1093/brain/awn345

LaMantia, A. S., and Purves, D. (1989). Development of glomerular pattern visualized in the olfactory bulbs of living mice. Nature 341, 646-649. doi: $10.1038 / 341646 \mathrm{a} 0$ 
Landis, B. N., Beutner, D., Frasnelli, J., Huttenbrink, K. B., and Hummel, T. (2005). Gustatory function in chronic inflammatory middle ear diseases. Laryngoscope 115, 1124-1127. doi: 10.1097/01.MLG.0000163750.72441.C3

Larsson, M., Farde, L., Hummel, T., Witt, M., Lindroth, N. E., and Backman, L. (2009). Age-related loss of olfactory sensitivity: association to dopamine transporter binding in putamen. Neuroscience 161, 422-426. doi: 10.1016/j.neuroscience.2009.03.074

Larsson, M., Finkel, D., and Pedersen, N. L. (2000). Odor identification: influences of age, gender, cognition, and personality. J. Gerontol. Psychol. Sci. Soc. Sci. 55 304-310. doi: 10.1093/geronb/55.5.P304

Larsson, M., Nilsson, L. G., Olofsson, J. K., and Nordin, S. (2004). Demographic and cognitive predictors of cued odor identification: evidence from a population-based study. Chem. Senses 29, 547-554. doi: 10.1093/chemse/bjh059

Larsson, M., Oberg, C., and Backman, L. (2006). Recollective experience in odor recognition: influences of adult age and familiarity. Psychol. Res. 70, 68-75. doi: 10.1007/s00426-004-0190-9

Lehnardt, S., Lehmann, S., Kaul, D., Tschimmel, K., Hoffmann, O., Cho, S., et al. (2007). Toll-like receptor 2 mediates CNS injury in focal cerebral ischemia. J. Neuroimmunol. 190, 28-33. doi: 10.1016/j.jneuroim.2007.07.023

Leopold, D. A., Hummel, T., Schwob, J. E., Hong, S. C., Knecht, M., and Kobal, G. (2000). Anterior distribution of human olfactory epithelium. Laryngoscope 110, 417-421. doi: 10.1097/00005537-200003000-00016

Levy, L. M., Degnan, A. J., Sethi, I., and Henkin, R. I. (2013). Anatomic olfactory structural abnormalities in congenital smell loss: magnetic resonance imaging evaluation of olfactory bulb, groove, sulcal, and hippocampal morphology. J. Comput. Assist. Tomogr. 37, 650-657. doi: 10.1097/RCT.0b013e31829bfa3b

Liberles, S. D., and Buck, L. B. (2006). A second class of chemosensory receptors in the olfactory epithelium. Nature. 442, 645-650. doi: 10.1038/nature05066

Liss, L., and Gomez, F. (1958). The nature of senile changes of the human olfactory bulb and tract. AMA Arch. Otolaryngol. 67, 167-171. doi: 10.1001/archotol.1958.00730010173006

London, B., Nabet, B., Fisher, A. R., White, B., Sammel, M. D., and Doty, R. L. (2008). Predictors of prognosis in patients with olfactory disturbance. Ann. Neurol. 63, 159-166. doi: 10.1002/ana.21293

Loo, A. T., Youngentob, S. L., Kent, P. F., and Schwob, J. E. (1996). The aging olfactory epithelium: neurogenesis, response to damage, and odorant-induced activity. Int. J. Dev. Neurosci. 14, 881-900. doi: 10.1016/S0736-5748(96)00046-9

Lotsch, J., and Hummel, T. (2006). The clinical significance of electrophysiological measures of olfactory function. Behav. Brain. Res. 170, 78-83. doi: 10.1016/j.bbr.2006.02.013

Mackay-Sim, A. (2003). "Neurogenesis in the olfactory neuroepithelium," in Handbook of Olfaction and Gustation. 2nd Edn., ed R. L. Doty (New York, NY: Marcel Dekker), 93-113.

Mackay-Sim, A. (2010). Stem cells and their niche in the adult olfactory mucosa. Arch. Ital. Biol. 148, 47-58.

Mackay-Sim, A., and Patel, U. (1984). Regional differences in cell density and cell genesis in the olfactory epithelium of the salamander, Ambystoma tigrinum. Exp. Brain Res. 57, 99-106. doi: 10.1007/BF00231136

Mair, R. G., Doty, R. L., Kelly, K. M., Wilson, C. S., Langlais, P. J., McEntee, W. J., et al. (1986). Multimodal sensory discrimination deficits in Korsakoff's psychosis. Neuropsychologia 24, 831-839. doi: 10.1016/0028-3932(86)90082-5

Malnic, B., Hirono, J., Sato, T., and Buck, L. B. (1999). Combinatorial receptor codes for odors. Cell 96, 713-723. doi: 10.1016/S0092-8674(00)80581-4

Matulionis, D. H. (1982). "Effects of the aging process on olfactory neuron plasticity," in Olfaction and Endocrine Regulation, ed W. Breipohl (London: IRL Press), 299-308.

McKeown, D. A., Doty, R. L., Perl, D. P., Frye, R. E., Simms, I., and Mester, A. (1996). Olfactory function in young adolescents with Down's syndrome. J. Neurol. Neurosurg. Psychiatry 61, 412-414. doi: 10.1136/jnnp.61.4.412

Meisami, E., Mikhail, L., Baim, D., and Bhatganar, K. (1998). Observations on glomeruli and mitral cell numbers and accessory olfactory bulb in adult and aging human olfactory bulbs. Proc. N.Y. Acad. Sci. 855, 708-715. doi: 10.1111/j.1749-6632.1998.tb10649.x

Menco, B. P. M., and Morrison, E. E. (2003). "Morphology of the mammalian olfactory epithelium: form, fine structure, function, and pathology," in Handbook of Olfaction and Gustation. 2nd Edn., ed R. L. Doty (New York, NY: Marcel Dekker), 17-49.

Menon, C., Westervelt, H. J., Jahn, D. R., Dressel, J. A., and O’Bryant, S. E. (2013). Normative Performance on the brief smell identification test (BSIT) in a multi-ethnic bilingual cohort: a project FRONTIER study. Clin. Neuropsychol. 27, 946-961. doi: 10.1080/13854046.2013.796406

Meurman, O. H. (1950). Experimental studies of the effect of pathological changes in the nasal mucous membrane on the olfactory bulb. Acta Otolaryngol. 38, 477-483. doi: 10.3109/00016485009118408

Mirza, N., Kroger, H., and Doty, R. L. (1997). Influence of age on the "nasal cycle." Laryngoscope 107, 62-66. doi: 10.1097/00005537-199701000-00014

Møller, P., and Dijksterhuis, G. (2003). Differential human electrodermal responses to odours. Neurosci. Lett. 346, 129-132. doi: 10.1016/S0304-3940(03)00498-1

Møller, P., Mojet, J., and Koster, E. P. (2007). Incidental and intentional flavor memory in young and older subjects. Chem. Senses 32, 557-567. doi: 10.1093/chemse/bjm026

Møller, P., Wulff, C., and Koster, E. P. (2004). Do age differences in odour memory depend on differences in verbal memory? Neuroreport 15, 915-917. doi: 10.1097/00001756-200404090-00036

Morgan, C. D., and Murphy, C. (2010). Differential effects of active attention and age on event-related potentials to visual and olfactory stimuli. Int. J. Psychophysiol. 78, 190-199. doi: 10.1016/j.ijpsycho.2010.07.008

Morrison, E. E., and Costanzo, R. M. (1990). Morphology of the human olfactory epithelium. J. Comp. Neurol. 297, 1-13. doi: 10.1002/cne.902970102

Murphy, C. (1983). Age-related effects on the threshold, psychophysical function, and pleasantness of menthol. J. Gerontol. 38, 217-222. doi: 10.1093/geronj/38.2.217

Murphy, C., Nordin, S., de, W. R., Cain, W. S., and Polich, J. (1994). Olfactoryevoked potentials: assessment of young and elderly, and comparison to psychophysical threshold. Chem. Senses 19, 47-56. doi: 10.1093/chemse/19.1.47

Murphy, C., Schubert, C. R., Cruickshanks, K. J., Klein, B. E., Klein, R., and Nondahl, D. M. (2002). Prevalence of olfactory impairment in older adults. JAMA 288, 2307-2312. doi: 10.1001/jama.288.18.2307

Naessen, R. (1971). An enquiry on the morphological characteristics and possible changes with age in the olfactory region of man. Acta Otolaryngol. 71, 49-62. doi: 10.3109/00016487109125332

Nagai, M., Wada, M., Usui, N., Tanaka, A., and Hasebe, Y. (2000). Pleasant odors attenuate the blood pressure increase during rhythmic handgrip in humans. Neurosci. Lett. 289, 227-229. doi: 10.1016/S0304-3940(00)01278-7

Nakano, I., and Hirano, A. (1983). Neuron loss in the nucleus basalis of Meynert in parkinsonism-dementia complex of Guam. Ann. Neurol. 13, 87-91. doi: 10.1002/ana.410130118

Nakano, I., and Hirano, A. (1984). Parkinson's disease: neuron loss in the nucleus basalis without concomitant Alzheimer's disease. Ann. Neurol. 15, 415-418. doi: 10.1002/ana.410150503

Nakashima, T., Kimmelman, C. P., and Snow, J. B. Jr. (1984). Structure of human fetal and adult olfactory neuroepithelium. Arch. Otolaryngol. 110, 641-646. doi: 10.1001/archotol.1984.00800360013003

Negoias, S., Croy, I., Gerber, J., Puschmann, S., Petrowski, K., Joraschky, P., et al. (2010). Reduced olfactory bulb volume and olfactory sensitivity in patients with acute major depression. Neuroscience 169, 415-421. doi: 10.1016/j.neuroscience.2010.05.012

Nguyen, A. D., Pelavin, P. E., Shenton, M. E., Chilakamarri, P., McCarley, R. W., Nestor, P. G., et al. (2011). Olfactory sulcal depth and olfactory bulb volume in patients with schizophrenia: an MRI study. Brain Imag. Behav. 5, 252-261. doi: 10.1007/s11682-011-9129-0

Nordin, S., Nyroos, M., Maunuksela, E., Niskanen, T., and Tuorila, H. (2002). Applicability of the scandinavian odor identification test: a Finnish-Swedish comparison. Acta Otolaryngol. 122, 294-297. doi: $10.1080 / 000164802753648187$

O'Connor, S., and Jacob, T. J. (2008). Neuropharmacology of the olfactory bulb. Curr. Mol. Pharmacol. 1, 181-190. doi: 10.2174/1874467210801030181

Olofsson, J., Ronnlund, M., Nordin, S., Hedner, M., Nilsson, L. G., Nyberg, L., et al. (2008). Odor identification impairment predicts cognitive decline and Alzheimer's disease. Int. J. Psychol. 43, 469.

Olofsson, J. K., Nordin, S., Wiens, S., Hedner, M., Nilsson, L. G., and Larsson, M. (2010). Odor identification impairment in carriers of ApoE-varepsilon4 is independent of clinical dementia. Neurobiol. Aging 31, 567-577. doi: 10.1016/j.neurobiolaging.2008.05.019

Olofsson, J. K., Ronnlund, M., Nordin, S., Nyberg, L., Nilsson, L. G., and Larsson, M. (2009). Odor identification deficit as a predictor of five-year global cognitive change: interactive effects with age and ApoE-epsilon4. Behav. Genet. 39, 496-503. doi: 10.1007/s10519-009-9289-5 
Osman, A., and Silas, J. (2014). "Electrophysiological measurement of olfactory function," in Handbook of Olfaction and Gustation, 3rd Edn., ed R. L. Doty (New York, NY: Wiley-Liss).

Ottoson, D. (1956). Analysis of the electrical activity of the olfactory epithelium. Acta Physiol. Scand. 35, 1-83.

Paik, S. I., Lehman, M. N., Seiden, A. M., Duncan, H. J., and Smith, D. V. (1992). Human olfactory biopsy. The influence of age and receptor distribution. Arch. Otolaryngol. Head Neck Surg. 118, 731-738. doi: 10.1001/archotol.1992.018800 70061012

Panni, P., Ferguson, I. A., Beacham, I., Mackay-Sim, A., Ekberg, J. A., and St. John, J. A. (2013). Phagocytosis of bacteria by olfactory ensheathing cells and Schwann cells. Neurosci. Lett. 539, 65-70. doi: 10.1016/j.neulet.2013.01.052

Peele, D. B., Allison, S. D., Bolon, B., Prah, J. D., Jensen, K. F., and Morgan, K. T. (1991). Functional deficits produced by 3-methylindole-induced olfactory mucosal damage revealed by a simple olfactory learning task. Toxicol. Appl. Pharmacol. 107, 191-202. doi: 10.1016/0041-008X(91)90202-P

Pelosi, P. (1994). Odorant-binding proteins. Crit. Rev. Biochem. Mol. Biol. 29, 199-228. doi: 10.3109/10409239409086801

Pinto, J. M., Schumm, L. P., Wroblewski, K. E., Kern, D. W., and McClintock, M. K. (2013). Racial disparities in olfactory loss among older adults in the United States. J. Gerontol. A Biol. Sci. Med. Sci. doi: 10.1093/gerona/glt063. [Ebub ahead of print].

Rawson, N. E., Gomez, G., Cowart, B., and Restrepo, D. (1998). The use of olfactory receptor neurons (ORNs) from biopsies to study changes in aging and neurodegenerative diseases. Ann. N.Y. Acad. Sci. 855, 701-707. doi: 10.1111/j.17496632.1998.tb10648.x

Rehn, B., Breipohl, W., Mendoza, A. S., and Apfelbach, R. (1986). Changes in granule cells of the ferret olfactory bulb associated with imprinting on prey odours. Brain Res. 373, 114-125. doi: 10.1016/0006-8993(86)90321-5

Richman, R. A., Post, E. M., Sheehe, P. R., and Wright, H. N. (1992). Olfactory performance during childhood. I. Development of an odorant identification test for children. J. Pediatr. 121, 908-911. doi: 10.1016/S0022-3476(05)80337-3

Rogers, J. D., Brogan, D., and Mirra, S. S. (1985). The nucleus basalis of Meynert in neurological disease: a quantitative morphological study. Ann. Neurol. 17, 163-170. doi: 10.1002/ana.410170210

Rolls, E. T., and Grabenhorst, F. (2008). The orbitofrontal cortex and beyond: from affect to decision-making. Prog. Neurobiol. 86, 216-244. doi: 10.1016/j.pneurobio.2008.09.001

Rombaux, P., Huart, C., Deggouj, N., Duprez, T., and Hummel, T. (2012). Prognostic value of olfactory bulb volume measurement for recovery in postinfectious and posttraumatic olfactory loss. Otolaryngol. Head Neck Surg. 147, 1136-1141. doi: 10.1177/0194599812459704

Rombaux, P., Martinage, S., Huart, C., and Collet, S. (2009). Post-infectious olfactory loss: a cohort study and update. B-ENT, 5(Suppl. 13), 89-95.

Rombaux, P., Potier, H., Bertrand, B., Duprez, T., and Hummel, T. (2008). Olfactory bulb volume in patients with sinonasal disease. Am. J. Rhinol. 22, 598-601. doi: 10.2500/ajr.2008.22.3237

Rosier, A., Dupont, P., Peuskens, J., Bormans, G., Vandenberghe, R., Maes, M., et al. (1996). Visualisation of loss of 5-HT2A receptors with age in healthy volunteers using $[18 \mathrm{~F}]$ altanserin and positron emission tomographic imaging. Psychiat. Res. 68, 11-22. doi: 10.1016/S0925-4927(96)02806-5

Ross, G. W., Petrovitch, H., Abbott, R. D., Tanner, C. M., Popper, J., Masaki, K., et al. (2008). Association of olfactory dysfunction with risk for future Parkinson's disease. Ann. Neurol. 63, 167-173. doi: 10.1002/ana.21291

Rouquier, S., Blancher, A., and Giorgi, D. (2000). The olfactory receptor gene repertoire in primates and mouse: evidence for reduction of the functional fraction in primates. Proc. Natl. Acad. Sci. U.S.A. 97, 2870-2874. doi: 10.1073/pnas.040580197

Rovee, C. K., Cohen, R. Y., and Shlapack, W. (1975). Life-span stability in olfactory sensitivity. Dev. Psychol. 11,311-318. doi: 10.1037/h0076566

Saito, H., Chi, Q., Zhuang, H., Matsunami, H., and Mainland, J. D. (2009). Odor coding by a Mammalian receptor repertoire. Sci. Signal. 2, ra9. doi: 10.1126/scisignal.2000016

Sajjadian, A., Doty, R. L., Gutnick, D. N., Chirurgi, R. J., Sivak, M., and Perl, D. (1994). Olfactory dysfunction in amyotrophic lateral sclerosis. Neurodegeneration 3, 153-157.

Sakakura, Y., Ukai, K., Majima, Y., Murai, S., Harada, T., and Miyoshi, Y. (1983). Nasal mucociliary clearance under various conditions. Acta Otolaryngol. 96, 167-173. doi: 10.3109/00016488309132888
Salihoglu, M., Kendirli, M. T., Altundag, A., Tekeli, H., Saglam, M., Cayonu, M., et al. (2013). The effect of obstructive sleep apnea on olfactory functions. Laryngoscope doi: 10.1002/lary.24565. [Epub ahead of print].

Sama, U. H., Tahir, M., and Lone, K. P. (2008). Age and gender-related differences in mitral cells of olfactory bulb. J. Coll. Physicians Surg. Pak. 18, 669-673.

Santos, D. V., Reiter, E. R., DiNardo, L. J., and Costanzo, R. M. (2004). Hazardous events associated with impaired olfactory function. Arch. Head Neck Surg. 130, 317-319. doi: 10.1001/archotol.130.3.317

Sawada, M., Kaneko, N., Inada, H., Wake, H., Kato, Y., Yanagawa, Y., et al. (2011). Sensory input regulates spatial and subtype-specific patterns of neuronal turnover in the adult olfactory bulb. J. Neurosci. 31, 11587-11596. doi: 10.1523/JNEUROSCI.0614-11.2011

Schiffman, S., and Pasternak, M. (1979). Decreased discrimination of food odors in the elderly. J. Gerontol. 34, 73-79. doi: 10.1093/geronj/34.1.73

Schiffman, S. S. (1991). Taste and smell losses with age. Bol. Asoc. Med. P.R. 83, $411-414$.

Schiffman, S. S., and Leffingwell, J. C. (1981). Perception of odors of simple pyrazines by young and elderly subjects: a multidimensional analysis. Pharmacol. Biochem. Behav. 14, 787-798. doi: 10.1016/0091-3057(81) 90362-2

Schiffman, S. S., Moss, J., and Erickson, R. P. (1976). Thresholds of food odors in the elderly. Exp. Aging Res. 2, 389-398. doi: 10.1080/03610737608257997

Schiffman, S. S., and Zervakis, J. (2002). Taste and smell perception in the elderly: effect of medication and disease. Adv. Food Nutr. Res. 44, 247-346. doi: 10.1016/S1043-4526(02)44006-5

Schliebs, R., and Arendt, T. (2011). The cholinergic system in aging and neuronal degeneration. Behav. Brain Res. 221, 555-563. doi: 10.1016/j.bbr.2010.11.058

Schmidt, F. A., Goktas, O., Harms, L., Bohner, G., Erb, K., Dahlslett, B., et al. (2011). Structural correlates of taste and smell loss in encephalitis disseminata. PLoS ONE 6:e19702. doi: 10.1371/journal.pone.0019702

Schriever, V. A., Reither, N., Gerber, J., Iannilli, E., and Hummel, T. (2013). Olfactory bulb volume in smokers. Exp. Brain Res. 225, 153-157. doi: 10.1007/s00221-012-3356-5

Schubert, C. R., Carmichael, L. L., Murphy, C., Klein, B. E., Klein, R., and Cruickshanks, K. J. (2008). Olfaction and the 5-year incidence of cognitive impairment in an epidemiological study of older adults. J. Am. Geriatr. Soc. 56, 1517-1521. doi: 10.1111/j.1532-5415.2008.01826.x

Schubert, C. R., Cruickshanks, K. J., Fischer, M. E., Huang, G. H., Klein, B. E., Klein, R., et al. (2012). Olfactory impairment in an adult population: the Beaver Dam Offspring Study. Chem. Senses 37, 325-334. doi: 10.1093/chemse/ bjr102

Schubert, C. R., Cruickshanks, K. J., Klein, B. E., Klein, R., and Nondahl, D. M. (2011). Olfactory impairment in older adults: five-year incidence and risk factors. Laryngoscope 121, 873-878. doi: 10.1002/lary.21416

Schumm, L. P., McClintock, M., Williams, S., Leitsch, S., Lundstrom, J., Hummel, T., et al. (2009). Assessment of sensory function in the national social life, health, and aging project. J. Gerontol. B Psychol. Sci. Soc. Sci. 64B (Suppl. 1), i76-i85. doi: 10.1093/geronb/gbp048

Schwab, J. A., and Zenkel, M. (1998). Filtration of particulates in the human nose. Laryngoscope 108, 120-124. doi: 10.1097/00005537-199801000-00023

Segura, B., Baggio, H. C., Solana, E., Palacios, E. M., Vendrell, P., Bargallo, N., et al. (2013). Neuroanatomical correlates of olfactory loss in normal aged subjects. Behav. Brain Res. 246, 148-153. doi: 10.1016/j.bbr.2013.02.025

Selkoe, D., and Kosik, K. (1984). "Neurochemical changes with aging," in Clinical Neurology of Aging, ed M. L. Albert (New York, NY: Oxford University Press), 53-75.

Settipane, G. A. (1996). Nasal polyps and immunoglobulin E (IgE). Allergy Asthma Proc. 17, 269-273. doi: 10.2500/108854196778662237

Shepherd, G. M. (1972). Synaptic organization of the mammalian olfactory bulb. Physiol. Rev. 52, 864-917.

Ship, J. A., Pearson, J. D., Cruise, L. J., Brant, L. J., and Metter, E. J. (1996). Longitudinal changes in smell identification. J. Gerontol. A Biol. Sci. Med. Sci. 51, M86-M91. doi: 10.1093/gerona/51A.2.M86

Ship, J. A., and Weiffenbach, J. M. (1993). Age, gender, medical treatment, and medication effects on smell identification. J. Gerontol. A. Biol. Sci. Med. Sci. 48, M26-M32. doi: 10.1093/geronj/48.1.M26

Sicard, G., and Holley, A. (1984). Receptor cell responses to odorants: similarities and differences among odorants. Brain Res. 292, 283-296. doi: 10.1016/00068993(84)90764-9 
Smith, C. G. (1935). The change in volume of the olfactory and accessory olfactory bulbs of the albino rat during postnatal life. J. Comp. Neurol. 61, 477-508. doi: 10.1002/cne.900610305

Smith, C. G. (1942). Age incidence of atrophy of olfactory nerves in man. J. Comp. Neurol. 77, 589-594. doi: 10.1002/cne.900770306

Smithson, L. J., and Kawaja, M. D. (2010). Microglial/macrophage cells in mammalian olfactory nerve fascicles. J. Neurosci. Res. 88, 858-865. doi: 10.1002/jnr. 22254

Somlyo, A. P., and Somlyo, A. V. (1968). Vascular smooth muscle. I. Normal structure, pathology, biochemistry, and biophysics. Pharmacol. Rev. 20, 197-272.

Staubert, C., Boselt, I., Bohnekamp, J., Rompler, H., Enard, W., and Schoneberg, T. (2010). Structural and functional evolution of the trace amine-associated receptors TAAR3, TAAR4 and TAAR5 in primates. PLoS ONE 5:e11133. doi: 10.1371/journal.pone.0011133

Stephan, A. B., Shum, E. Y., Hirsh, S., Cygnar, K. D., Reisert, J., and Zhao, H. (2009). ANO2 is the cilial calcium-activated chloride channel that may mediate olfactory amplification. Proc. Natl. Acad. Sc.i U.S.A. 106, 11776-11781. doi: 10.1073/pnas.0903304106

Stevens, J. C., and Cain, W. S. (1985). Age-related deficiency in the perceived strength of 6 odorants. Chem. Senses 10, 517-529. doi: 10.1093/chemse/10.4.517

Stevens, J. C., Cain, W. S., and Weinstein, D. E. (1987). Agining impairs the ability to detect gas odor. Fire Technol. 23, 198-204. doi: 10.1007/BF01036936

Stevens, J. C., Plantinga, A., and Cain, W. S. (1982). Reduction of odor and nasal pungency associated with aging. Neurobiol. Aging 3, 125-132. doi: 10.1016/0197-4580(82)90008-2

Strauss, E. L. (1970). A study on olfactory acuity. Ann. Otol. Rhinol. Laryngol. 79, 95-104.

Strong, R. (1998). Neurochemical changes in the aging human brain: implications for behavioral impairment and neurodegenerative disease. Geriatrics 53(Suppl. 1), S9-S12.

Stuck, B. A., Frey, S., Freiburg, C., Hormann, K., Zahnert, T., and Hummel, T. (2006). Chemosensory event-related potentials in relation to side of stimulation, age, sex, and stimulus concentration. Clin. Neurophysiol. 117, 1367-1375. doi: 10.1016/j.clinph.2006.03.004

Suzuki, Y., Critchley, H. D., Suckling, J., Fukuda, R., Williams, S. C., Andrew, C., et al. (2001). Functional magnetic resonance imaging of odor identification: the effect of aging. J. Gerontol. A Biol. Sci. Med. Sci. 56, M756-M760. doi: 10.1093/gerona/56.12.M756

Takagi, S. F. (1989). Standardized olfactometries in Japan - a review over ten years. Chem. Senses 14, 25-46. doi: 10.1093/chemse/14.1.25

Tang, S. C., Arumugam, T. V., Xu, X., Cheng, A., Mughal, M. R., Jo, D. G., et al. (2007). Pivotal role for neuronal Toll-like receptors in ischemic brain injury and functional deficits. Proc. Natl. Acad. Sci. U. S. A 104, 13798-13803. doi: 10.1073/pnas.0702553104

Thesen, T., and Murphy, C. (2001). Age-related changes in olfactory processing detected with olfactory event-related brain potentials using velopharyngeal closure and natural breathing. Internat J. Psychophysiol. 40, 119-127. doi: 10.1016/S0167-8760(00)00157-4

Thomann, P. A., Dos, S. V., Seidl, U., Toro, P., Essig, M., and Schroder, J. (2009). MRI-derived atrophy of the olfactory bulb and tract in mild cognitive impairment and Alzheimer's disease. J. Alzheimers Dis. 17, 213-221. doi: 10.3233/JAD2009-1036

Tourbier, I. A., and Doty, R. L. (2007). Sniff magnitude test: relationship to odor identification, detection, and memory tests in a clinic population. Chem. Senses 32, 515-523. doi: 10.1093/chemse/bjm020

Turetsky, B. I., Moberg, P. J., Arnold, S. E., Doty, R. L., and Gur, R. E. (2003). Low olfactory bulb volume in first-degree relatives of patients with schizophrenia. Am. J. Psychiatry 160, 703-708. doi: 10.1176/appi.ajp.160.4.703

Van Toller, S., and Dodd, G. H. (1987). Presbyosmia and olfactory compensation for the elderly. Brit. J. Clin. Pract. 41, 725-728.

Velayudhan, L., Pritchard, M., Powell, J. F., Proitsi, P., and Lovestone, S. (2013). Smell identification function as a severity and progression marker in Alzheimer's disease. Int. Psychogeriatr. 25, 1157-1166. doi: $10.1017 /$ S1041610213000446

Venstrom, D., and Amoore, J. E. (1968). Olfactory threshold in relation to age, sex or smoking. J. Food Sci. 33, 264-265. doi: 10.1111/j.1365-2621.1968.tb01364.x

Vogalis, F., Hegg, C. C., and Lucero, M. T. (2005). Ionic conductances in sustentacular cells of the mouse olfactory epithelium. J. Physiol 562, 785-799. doi: 10.1113/jphysiol.2004.079228
Vogels, O. J., Broere, C. A., ter Laak, H. J., ten Donkelaar, H. J., Nieuwenhuys, R., and Schulte, B. P. (1990). Cell loss and shrinkage in the nucleus basalis Meynert complex in Alzheimer's disease. Neurobiol. Aging 11, 3-13. doi: 10.1016/01974580(90)90056-6

Volkow, N. D., Logan, J., Fowler, J. S., Wang, G. J., Gur, R. C., Wong, C., et al. (2000). Association between age-related decline in brain dopamine activity and impairment in frontal and cingulate metabolism. Am. J. Psychiatry 157, 75-80. doi: 10.1176/appi.ajp.157.10.1709

Wang, C., Liu, F., Liu, Y. Y., Zhao, C. H., You, Y., Wang, L., et al. (2011a). Identification and characterization of neuroblasts in the subventricular zone and rostral migratory stream of the adult human brain. Cell Res. 21, 1534-1550. doi: $10.1038 / \mathrm{cr} .2011 .83$

Wang, J., Eslinger, P. J., Smith, M. B., and Yang, Q. X. (2005). Functional magnetic resonance imaging study of human olfaction and normal aging. J. Gerontol. A Biol. Sci. Med. Sci. 60, 510-514. doi: 10.1093/gerona/60.4.510

Wang, J., You, H., Liu, J. F., Ni, D. F., Zhang, Z. X., and Guan, J. (2011b). Association of olfactory bulb volume and olfactory sulcus depth with olfactory function in patients with Parkinson disease. AJNR Am. J. Neuroradiol. 32, 677-681. doi: 10.3174/ajnr.A2350

Watabe-Rudolph, M., Begus-Nahrmann, Y., Lechel, A., Rolyan, H., Scheithauer, M. O., Rettinger, G., et al. (2011). Telomere shortening impairs regeneration of the olfactory epithelium in response to injury but not under homeostatic conditions. PLoS ONE 6:e27801. doi: 10.1371/journal.pone.0027801

Wehling, E., Nordin, S., Espeseth, T., Reinvang, I., and Lundervold, A. J. (2011). Unawareness of olfactory dysfunction and its association with cognitive functioning in middle aged and old adults. Arch. Clin Neuropsychol. 26, 260-269. doi: 10.1093/arclin/acr019

Weierstall, R., and Pause, B. M. (2012). Development of a 15-item odour discrimination test (Dusseldorf Odour Discrimination Test). Perception 41, 193-203. doi: $10.1068 / \mathrm{p} 7113$

Wenning, G. K., Shephard, B., Hawkes, C., Petruckevitch, A., Lees, A., and Quinn, N. (1995). Olfactory function in atypical parkinsonian syndromes. Acta Neurol. Scand. 91, 247-250. doi: 10.1111/j.1600-0404.1995.tb06998.x

Wilson, R. S., Arnold, S. E., Schneider, J. A., Tang, Y., and Bennett, D. A. (2007a). The relationship between cerebral Alzheimer's disease pathology and odour identification in old age. J. Neurol. Neurosurg. Psychiatry 78, 30-35. doi: 10.1136/jnnp.2006.099721

Wilson, R. S., Schneider, J. A., Arnold, S. E., Tang, Y., Boyle, P. A., and Bennett, D. A. (2007b). Olfactory identification and incidence of mild cognitive impairment in older age. Arch. Gen. Psychiatry 64, 802-808. doi: 10.1001/archpsyc.64.7.802

Wilson, R. S., Yu, L., and Bennett, D. A. (2011a). Odor identification and mortality in old age. Chem. Senses 36, 63-67. doi: 10.1093/chemse/bjq098

Wilson, R. S., Yu, L., Schneider, J. A., Arnold, S. E., Buchman, A. S., and Bennett, D. A. (2011b). Lewy bodies and olfactory dysfunction in old age. Chem. Senses 36, 367-373. doi: 10.1093/chemse/bjq139

Wong, K. K., Muller, M. L., Kuwabara, H., Studenski, S. A., and Bohnen, N. I. (2010). Olfactory loss and nigrostriatal dopaminergic denervation in the elderly. Neurosci. Lett. 484, 163-167. doi: 10.1016/j.neulet.2010.08.037

Wysocki, C. J., and Gilbert, A. N. (1989). National geographic smell survey. Effects of age are heterogenous. Ann. N.Y. Acad. Sci. 561, 12-28. doi: 10.1111/j.17496632.1989.tb20966.x

Yoshida, M. (1984). Correlation analysis of detection threshold data for "standard test" odors. Bull. Fac. Sci. Eng. Cho. Univ. 27, 343-353.

Yoshida, M., Murakami, N., Hashizume, Y., and Takahashi, A. (1992). A clinicopathological study on 13 cases of motor neuron disease with dementia. Rinsho Shinkeigaku 32, 1193-1202.

Yousem, D. M., Geckle, R., and Doty, R. L. (1995a). MR of patients with posttraumatic olfactory deficits. Chem. Senses 20, 338.

Yousem, D. M., Geckle, R. J., and Doty, R. L. (1995b). Evaluation of olfactory deficits in neurodegenerative disorders. Radiology 197, 173.

Yousem, D. M., Geckle, R. J., Bilker, W. B., and Doty, R. L. (1998). Olfactory bulb and tract and temporal lobe volumes. Normative data across decades. Ann. N.Y. Acad. Sci. 855, 546-555. doi: 10.1111/j.1749-6632.1998.tb10624.x

Yousem, D. M., Geckle, R. J., Bilker, W., McKeown, D. A., and Doty, R. L. (1996). MR evaluation of patients with congenital hyposmia or anosmia. Am. J. Roentgenol. 166, 439-443. doi: 10.2214/ajr.166.2.8553963

Yousem, D. M., Maldjian, J. A., Hummel, T., Alsop, D. C., Geckle, R. J., Kraut, M. A., et al. (1999). The effect of age on odor-stimulated functional MR imaging. AJNR Am. J. Neuroradiol. 20, 600-608. 
Yousem, D. M., Turner, W. J., Li, C., Snyder, P. J., and Doty, R. L. (1993). Kallmann syndrome: MR evaluation of olfactory system. AJNR Am. J. Neuroradiol. 14, 839-843.

Zald, D. H. (2006). "Neuropsychological assessment of the orbitofrontal cortex," in The Orbitofrontal Cortex, eds D. H. Zald and S. L. Rauch (New York, NY: Oxford University Press), 449-480. doi: 10.1093/acprof:oso/9780198565741.001.0001

Ziegler, G., Harhausen, D., Schepers, C., Hoffmann, O., Rohr, C., Prinz, V., et al. (2007). TLR2 has a detrimental role in mouse transient focal cerebral ischemia. Biochem. Biophys. Res Commun. 359, 574-579. doi: 10.1016/j.bbrc.2007.05.157

Zielinski, B. S., Getchell, M. L., Wenokur, R. L., and Getchell, T. V. (1989). Ultrastructural localization and identification of adrenergic and cholinergic nerve terminals in the olfactory mucosa. Anat. Rec. 225, 232-245. doi: 10.1002/ar.1092250309

Conflict of Interest Statement: Dr. Doty is the President of, and major shareholder in, Sensonics International, a corporation that manufactures and distributes chemosensory test equipment and products, including the commercial version of the University of Pennsylvania Smell Identification Test (UPSIT) and a number of its clones. Dr. Kamath declares no commercial or financial relationships that could be construed as a potential conflict of interest.

Received: 23 October 2013; accepted: 08 January 2014; published online: 07 February 2014.

Citation: Doty RL and Kamath V (2014) The influences of age on olfaction: a review. Front. Psychol. 5:20. doi: 10.3389/fpsyg.2014.00020

This article was submitted to Cognitive Science, a section of the journal Frontiers in Psychology.

Copyright (c) 2014 Doty and Kamath. This is an open-access article distributed under the terms of the Creative Commons Attribution License (CC BY). The use, distribution or reproduction in other forums is permitted, provided the original author(s) or licensor are credited and that the original publication in this journal is cited, in accordance with accepted academic practice. No use, distribution or reproduction is permitted which does not comply with these terms. 